\title{
ENDOGENOUS GROWTH THROUGH INVESTMENT-SPECIFIC Technological Change
}

by

\author{
Gregory W. Huffman
}

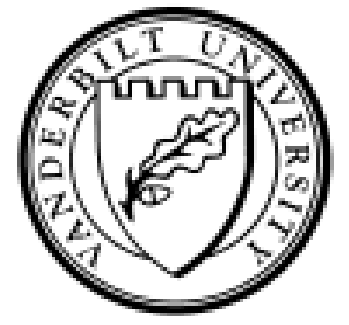

Working Paper No. 02-W18R

July 2002

Revised November 2002

DEPARTMENT OF ECONOMICS

VANDERBILT UNIVERSITY

NASHVILLE, TN 37235

www.vanderbilt.edu/econ 


\title{
Endogenous Growth Through Investment-Specific Technological Change
}

\author{
Gregory W. Huffman*
}

November 18, 2002

\begin{abstract}
This paper examines a model in which growth takes place through investment-specific technological change, which in turn is determined endogenously through research spending. In particular, the role of the degree of substitutability between research spending and new capital construction is explored. It is shown that the effect of a change in the capital tax rate on the growth rate can depend on the degree of substitability between research spending and new capital construction. Research subsidies tend to have a larger impact on the growth rate than would an investment tax credit of the same magnitude. Increases in the capital tax rate can increase the growth rate of the economy, even in the absence of externalities. In contrast to the existing literature, the welfare cost of capital taxation in this model can be negligible. There may be multiple tax rates on capital that achieve the same growth rates. It is demonstrated that in the presence of certain types of positive externalities, the optimal growth rate can be attained through the use of capital taxes - rather than subsidies.
\end{abstract}

\section{Introduction}

There has been a considerable growth in the last decade, of models that seek to enhance our understanding of the mechanisms that influence growth in economies. There is also some considerable evidence that technological change comes largely in the form of advances in the manner that capital is produced. This paper seeks to join these two literatures so as to understand the role played investment specific technological change in generating growth through some endogenous mechanism. Within the context of a model with these features, it is shown that a change in the tax rate on capital can have a much different impact than one would normally find in other more traditional growth models.

\footnotetext{
* Vanderbilt University
} 
There is abundant evidence that technological innovation leads to the development of new types or vintages of capital, and that this development is indeed an important engine of growth. This is perhaps most evident in the area of computers where succeeding generations of the product lead to dramatic increases in computational efficiency, at little or no attendant increase in cost (e.g. see Jorgenson [7]). This type of technological innovation is different from the usual changes in total factor productivity in which capital of different generations is thought of as being the same type of good, or having the same cost as previous vintages of capital (i.e. as measured in units of the consumption good). It is the thesis of this paper that research and development spending helps produce new types of capital which are more productive or efficient than previous versions. The fact that this is an important source of economic growth has been well-documented (see Greenwood, Hercowitz, and Krusell [4]). This latter research has built on the earlier empirical findings of Gordon [2]. Furthermore, although it is obvious that there have been dramatic technological advances in the area of production of equipment, which has been largely driven by innovations in the computer-related areas, Gort, Greenwood, and Rupert [3] also show that there have also been similar advances - though perhaps not as dramatic - in the area of capital structures as well. ${ }^{1}$

These papers take as given the process for the fall in the relative price of certain types of capital goods, to show that this effect is sufficiently large as to explain a considerable fraction of observed growth, even in the absence of such other effects such as changes in total factor productivity. However, in these papers there is no link between any endogenous decisions, such as research and development spending, and the resulting fall in the relative price of capital. It is the role of this paper to explore this relationship since it seems obvious that new technologies, or new types of capital, are developed because of the high prospective return that they can generate. Furthermore, it is of interest to explore the relationship between research spending, and capital investment from a fiscal policy perspective. It is then possible to answer such questions as "How much of a subsidy to research spending is necessary to 'offset' the distortion imposed by a specific capital tax?" Also, it is then possible to quantify the importance of research spending, in the same manner that it is possible to quantify the effect or role of the capital stock.

\footnotetext{
${ }^{1}$ In fact, Greenwood, Hercowitz and Krusell [4] find that when changes in the real price of capital are taken into account, there appears to have been negative growth in total factor productivity since 1965. This is despite the fact that they assume that there has been a fall in the relative cost of producing equipment, but not structures. However, the subsequent findings of Gort, Greenwood, and Rupert [3] suggest that there have been similar advances in the area of structures. In light of this, it would seem that the findings of Greenwood, Hercowitz and Krusell should be read so as to cast considerable doubt on there being much of a remaining role at all for total factor productivity in explaining aggregate economic growth.
} 
Lucas [9], as well as Stokey and Rebelo [12] explore the effect that various tax rates can have on the growth rate of an economy, for various configurations of the parameters of the economy. They find that although capital taxation can have a considerable impact on welfare, the growth rate effects may not be substantial. Stokey and Rebelo also find that the values for the elasticities of substitution in production do not appear to matter for these results. However, these authors do not explore the importance of the elasticities considered here: namely, the elasticity of substitution between new capital construction and research spending.

The results of this paper support their findings that capital taxation may not have a substantially negative impact on the growth rate. However, the results found here cast doubt as to whether the welfare costs of capital taxation are as large as has been previously thought.

It is shown below that the effect of capital taxation can be quite different in a model in which new technologies are generated endogenously through research spending. Even in the case in which there are no externalities, and in which allocations are optimal, it can be the case that an increase in capital taxation can increase the growth rate. For some economies, there is a growth-maximizing tax rate on capital that is an interior solution (i.e. between zero and one). The model then can explain why it may be possible to have two otherwise identical economies, but which have quite different levels of capital taxation, which nevertheless display the same level of economic growth and have the same rate of return to capital. Furthermore, for some types of positive externalities, the optimum growth rate can be achieved through a positive capital tax. Therefore this paper is an attempt to develop an answer to a positive question: Given that so many dynamic economic models seem to imply that capital taxation is distortional and imposes such high welfare costs, why is that the taxation of capital is so pervasive?

The remainder of this paper is organized as follows. In the following section the basic model is presented, and it is shown that this economy can exhibit balanced growth. In the next section government taxation is added to the model to investigate how government policies can influence the equilibrium growth rate. It is shown that research subsidies appear to have a much larger impact on the growth rate, than do investment tax credits of the same size. Furthermore, it is shown that the growth rate is not necessarily monotonic in the capital tax rate. Increases in the tax rate on capital tax rate may lower or raise the growth rate, if research spending is expensed, or tax-deductible. It is then shown that if there are positive externalities in research spending, it may be desirable for the government to impose a capital tax rate in order to motivate firms to substitute research spending for investment spending. 


\section{The General Model}

The model is a variant of the traditional growth model. There is no uncertainty, and time is discrete. To simplify the analysis, at first the analysis will neglect any role for government. There is a continuum of identical agents, each of whom has preferences that are characterized by the following constant relative risk-aversion utility function

$$
\sum_{t=1}^{\infty} \beta^{t}\left(\frac{c_{t}^{1-\sigma}-1}{1-\sigma}\right),
$$

for $\beta \in(0,1), \sigma \geq 0$, and $c_{t}$ denotes the quantity of consumption.

The production technology is primitive. To make things simple, output in period $t$ is produced from capital alone, and is described as follows: $y_{t}=A k_{t}^{\alpha}$. The analysis will be carried-out in per-capita terms, and therefore it will be assumed that each individual owns a production function or technology of this sort. Despite the fact that there are diminishing returns to scale, the economy can still display balanced growth. Because of the diminishing marginal returns, the decentralization of a competitive equilibrium is straightforward.

Output can be consumed, used for the construction of new capital or for the research activity. However, the production of capital can be accomplished by either investing in an existing capital technology, producing a new technology, or engaging in some measure of both activities. Furthermore, the relative cost (or return) of investing, or developing a new technology, can be influenced by the amount of resources that are devoted to research spending. That is, there is a finite elasticity of substitution between these two activities. To accomplish this, let the resource constraint be described as follows:

$$
c_{t}+v_{t}+\Psi\left(i_{t}, V_{t}\right) \leq y_{t}=A k_{t}^{\alpha} .
$$

Here $V_{t}$ denotes the stock of research knowledge in period $t$. Research spending in period $t$ is denoted $v_{t}$, and this will add to the stock research knowledge in the subsequent period. ${ }^{2}$ Also, $i_{t}$ denotes the level of new capital construction in period $t$, measured in units of new capital created. The function $\Psi(\cdot, \cdot)$ is the amount of investment measured in units of the consumption good. However, it

\footnotetext{
${ }^{2}$ It may be useful to think of $v_{t}$ as the amount of real resources devoted to the development of new technologies, so it seems reasonable to ascribe the term "research spending" to describe this activity. In contrast, $V_{t}$ is the accumulated effect of past research, so it also seems reasonable to refer to it as the stock of research knowledge.
} 
is, in a sense, also a cost function for the production of the new capital. This technology for the cost function is then characterized as follows:

$$
\Psi\left(i_{t}, V_{t}\right)=B\left[(1-\theta) i_{t}^{\frac{\rho}{(1-\theta)}}+\theta\left(V_{t}\right)^{\rho}\right]^{1 / \rho}
$$

That implies that the cost of undertaking producing new capital depends on the amount of research spending that has been previously undertaken. It is assumed that $\theta \leq 0$, so that the cost function is increasing in $i_{t}$, and decreasing in $V_{t}$. That is, the larger is the stock of research knowledge, the cheaper it is to produce a specific amount of new capital.

It is assumed that output from each technology, which is not consumed by the individual, must be used, via the companion function $\Psi(\cdot, \cdot)$, to produce new capital, or augment the stock of knowledge of that individual. In this sense, construction and research expenditures are individual specific. That is, agents cannot "pool" these activities, and must spend on their own research activities, in order to lower the cost of constructing their own capital. ${ }^{3}$ Capital, on the other hand, is freely tradeable among agents, and therefore the rates of return across the different production functions will be equated.

Obviously $\rho$ influences the degree to which there is substitutability between new capital construction and research spending. In Appendix A it is shown that in fact $1 /(1-\rho)$ is the elasticity of substitution between real investment, and real spending on research. The parameter restrictions that are necessary are that $\rho \leq 1$, and $\theta<0$. If $\rho=1$, then there is an infinite elasticity of substitution between research spending and investment. That is, these two activities are perfect substitutes. If $\rho \rightarrow-\infty$, then investment and research spending are complementary. An intermediate case to consider is $\rho=0$, in which case the function $\Psi(\cdot, \cdot)$ becomes $B\left(V_{t}^{\theta}\right) i_{t}$.

There is also the usual capital evolution equation, which is written as follows

$$
k_{t+1}=(1-\delta) k_{t}+i_{t}
$$

where $\delta$ is the depreciation rate. In addition, there is the following companion equation that determines how the stock of research spending influences the level of research knowledge ${ }^{4}$

\footnotetext{
${ }^{3}$ This means that there is no free-rider problem or externality in the production of investment goods, so that one person could do all the research which would then benefit everyone.

${ }^{4}$ It would considerably simplify the model to suppose that research spending fully depreciates after one period, so that $V_{t+1}=v_{t}$, so that research spending only has a one-period impact. In this case it is only last period's research that determines this period's price of capital. Many of the qualitative features of the model presented below would still be preserved. However, this would introduce a complication when it comes to taking seriously the empirical implications of the model in Section 3 below because it would lead to too high a level of research spending, as a fraction of aggregate
} 


$$
V_{t+1}=V_{t}+v_{t}
$$

As mentioned above, one should interpret the function $\Psi(\cdot, \cdot)$ in equation $(2.2)$ as the real cost of undertaking the production of $i_{t}$ units of new investment, measured in (real) units of the consumption good. This is to be distinguished from capital, which is measured in an entirely different type of units. ${ }^{5}$ In this sense, the expression $\Psi\left(i_{t}, V_{t}\right)$ should be interpreted as a cost function, given $V_{t}$, for producing new capital $\left(i_{t}\right){ }^{6}$ Although it is tempting to refer to $\left(i_{t}\right)$ as investment, this is misleading because it is not being measured in units of the consumption good, but in units of the capital good. Due to the fact that research spending can alter the cost of producing new capital (i.e. can influence the relative price), the stock of capital will be measured in units other than that of the consumption good. With the functional form adopted in equation (2.3), it is possible to show that the relative size of the amount of investment $(\Psi(\cdot, \cdot))$ will be a constant fraction of aggregate output - as appears to be true of observed investment. As will be shown below this function will capture both price or quality adjustments, as well as quantity changes in capital.

The process through which growth takes place is as follows. Associated with each production technology owned by the individual, is a related technology that takes research knowledge as an input, and this technology determines the rate at which the consumption good is transformed into capital. The stock of research knowledge in period $t$, denoted $V_{t}$, helps to lower the cost of producing capital in the subsequent period. Research spending by an individual affects his future ability to transform the consumption good into capital, but does not affect the ability of other individuals to do the same.

Furthermore, as long as $\rho$ is not too close to unity, it is easy to see that research spending is vital to having growth in this economy. That is, inspection of equation (2.2) reveals that if $V_{t}$ is held constant for all time periods, then the concavity of the production function destroys the possibility of growth. If $\rho$ is sufficiently large negative number, then it is possible to see that even an increment to the capital stock is impossible without joint increases in both research and investment (see Appendix A).

Although human capital will not be incorporated into the model, this is not because it is unimpor-

output.

${ }^{5}$ This could also be interpreted as an economy in which there are adjustment costs in the production of new capital. See Appendix A for another interpretation.

${ }^{6}$ It should be noted that with the usual neutral technological change, or total factor productivity shock (i.e. the ' $z$ ' in the technology $z F(k)$ ), an increase in the technology shock itself results in increased output, even when the other factors of production are held fixed. By contrast, with investment-specific technological change, increased output results only if the technology is adopted through further capital accumulation. 
tant. Instead this will allow us to simplify the analysis and focus on the interaction between growth and capital accumulation on the one hand, and the development of new types of capital on the other.

It should also be noted that the model is not unconventional. In fact, in the instance in which $\alpha=1$, which implies that $\theta=0$ (as is shown below), this model collapses to the "A-K" model.

\subsection{The Optimization Conditions}

It is illuminating to analyze the optimization conditions for this problem. The objective function is concave, and the constraints are convex, so that an optimum is described by the first order conditions. These conditions will be analyzed, while assuming that these conditions hold with equality. It is straightforward to verify that the condition for optimal capital accumulation is written as follows:

$$
\begin{gathered}
{\left[i_{t}^{\left(\frac{\rho}{1-\theta}\right)-1}\right] B\left[(1-\theta) i_{t}^{\frac{\rho}{(1-\theta)}}+\theta\left(V_{t}\right)^{\rho}\right]^{(1 / \rho)-1}\left(c_{t}\right)^{-\sigma}=} \\
\beta\left(c_{t+1}\right)^{-\sigma}\left[A \alpha k_{t+1}^{\alpha-1}+(1-\delta)\left[i_{t+1}^{\left(\frac{\rho}{1-\theta}\right)-1}\right] B\left[(1-\theta) i_{t+1}^{\frac{\rho}{(1-\theta)}}+\theta\left(V_{t+1}\right)^{\rho}\right]^{(1 / \rho)-1}\right]
\end{gathered}
$$

This is a little bit different from the usual version of the euler equation - but not much. Essentially it says that the marginal cost of a unit of investment in period $t$ must equal the subsequent return in the following period. The major difference is that these costs and returns have to be adjusted for the quantity of research activity that is being undertaken. This means that there is a quality change in capital from period to period.

The optimization condition for research spending is then written as follows:

$$
\begin{aligned}
\left(c_{t}\right)^{-\sigma} & =\beta\left(c_{t+1}\right)^{-\sigma}\left[(-B \theta)\left(V_{t+1}^{\rho-1}\right)\left[(1-\theta) i_{t+1}^{\frac{\rho}{(1-\theta)}}+\theta\left(V_{t+1}\right)^{\rho}\right]^{(1 / \rho)-1}+1\right] \\
& =\sum_{j=1}^{\infty} \beta^{i}\left(c_{t+j}\right)^{-\sigma}(-B \theta)\left(V_{t+j}^{\rho-1}\right)\left[(1-\theta) i_{t+j}^{\frac{\rho}{(1-\theta)}}+\theta\left(V_{t+j}\right)^{\rho}\right]^{(1 / \rho)-1}
\end{aligned}
$$

The interpretation of this is that raising research spending $\left(v_{t}\right)$ by one unit has the effect of raising the value or amount of new capital that can be produced in the subsequent periods. Furthermore, as 
this equation demonstrates, research spending in one period has a persistent effect, in that it lowers the cost of producing capital not just in the following period, but in all future periods.

It is more enlightening to re-write these two optimization conditions. First, note that the "price" of a new unit of investment, in units of the consumption good can be written more succinctly as follows

$$
q_{t} \equiv \frac{\partial \Psi\left(i_{t}, V_{t}\right)}{\partial i_{t}}=B\left[i_{t}^{\left(\frac{\rho}{1-\theta}\right)-1}\right]\left[(1-\theta) i_{t}^{\frac{\rho}{(1-\theta)}}+\theta\left(V_{t}\right)^{\rho}\right]^{(1 / \rho)-1}
$$

It is easily seen that $\partial q_{t} / \partial V_{t}<0$, since $\theta<0$. In other words, increasing the level of research activity lowers the cost of producing new capital. Equation (2.6) can then be re-written as follows

$$
q_{t}\left(c_{t}\right)^{-\sigma}=\beta\left(c_{t+1}\right)^{-\sigma}\left[A \alpha k_{t+1}^{\alpha-1}+(1-\delta) q_{t+1}\right]
$$

Here, increasing the amount of investment in period $t$ costs $q_{t}$ units of the consumption good. This produces $A \alpha k_{t+1}^{\alpha-1}$ units of the consumption good. The real value of this new capital in the subsequent period, in units of the consumption good, is then $(1-\delta) q_{t+1}$. Since the real price of new capital falls each period (i.e. $q_{t+1}<q_{t}$ ), this type of technological change acts like increased depreciation. In other words, the return to investing in new capital is diminished because of the prospect that, due to new technological innovations, it will be cheaper to produce that unit of capital in the subsequent period.

Also, note that the "return" in period $t$, from undertaking an extra unit of research spending in the prior period can be written as follows:

$$
R_{t} \equiv-\frac{\partial \Psi\left(i_{t}, V_{t}\right)}{\partial V_{t}}=-B \theta\left[V_{t}^{\rho-1}\right]\left[(1-\theta) i_{t}^{\frac{\rho}{(1-\theta)}}+\theta\left(V_{t}\right)^{\rho}\right]^{(1 / \rho)-1}
$$

Similarly, equation (2.7) can be re-written as follows

$$
\left(c_{t}\right)^{-\sigma}=\sum_{i=1}^{\infty} \beta^{i}\left(c_{t+i}\right)^{-\sigma} R_{t+i} .
$$

This expression means that increasing research spending in period $t$ lowers the cost of producing new capital in the subsequent periods. This in turn raises the return to investing in period $t+1$, because of the lower cost of converting output into new capital goods. Furthermore, the return to research spending is higher if one anticipates undertaking a larger quantity of investment in the following period.

Another interpretation of the variable $R_{t}$ would be as follows. Let the function from equation (2.8) 
be written as $q\left(i_{t}, V_{t}\right)$. Then, the total amount of investment, necessary to produce $i_{t}$ units of capital, can be written as follows

$$
\int q\left(i_{t}, V_{t}\right) d i_{t}=\Psi\left(i_{t}, V_{t}\right)
$$

This is really like adding-up the value of each unit of new capital created, measured in units of the consumption good. Here, then the variable $R_{t}$ can then be written as follows:

$$
R_{t}=-\frac{d \Psi\left(i_{t}, V_{t}\right)}{d V_{t}}=-\frac{d\left[\int q\left(i_{t}, V_{t}\right) d i_{t}\right]}{d V_{t}}=-\int\left[\frac{d q\left(i_{t}, V_{t}\right)}{d V_{t}}\right] d i_{t} .
$$

Viewed from this perspective, it is clear that the return from producing another unit of research spending is that it would decrease the marginal cost of producing each of the units of new capital that will be generated in the following periods.

Here research spending in period $t$ lowers the cost of producing capital next period (i.e. lowers $q_{t+1}$ ), which in turn lowers the cost of investment in period $t+1$. Of course, the return from research spending is greater, the larger is the amount of investment $\left(i_{t+1}\right)$ that is expected to take place. But research spending in period $t$ which lowers $q_{t+1}$, also works to lower the return to investment in capital in the same period (i.e. period $t$ ), as illustrated by the presence of $q_{t+1}$ on the right side of equation (2.9). In other words, one "cost" of investing in capital in period $t$ is that the cost of undertaking this same production of new capital will be even lower in subsequent periods. There is certainly a delay in the return to research spending: increased research spending in period $t$ enables investment to be undertaken more cheaply in period $t+1$, which will then raise the level of output in period $t+2$. Research spending itself does not produce any future output, but merely complements or facilitates the production of output induced through capital accumulation in future periods.

The above two conditions suggest the following interesting behavior. Past research spending $\left(v_{t-1}\right)$ increases the incentive for new capital construction $\left(i_{t}\right)$ because it lowers the cost of creating new capital $\left(q_{t}\right)$. However, contemporaneous research spending $\left(v_{t}\right)$ discourages new capital construction because it lowers the return by lowering the future price $\left(q_{t+1}\right)$ of this capital. This suggests that the immediate removal of government subsidies to research, hence lowering $v_{t}$, might have the effect of raising contemporaneous investment because this would raise the future value of capital $\left(q_{t+1}\right)$.

It will be convenient to think of research spending as having the following effect. In period $t$, the cost of producing a unit of capital, with the best available technology, is $q_{t}$ units of the consumption good. One interpretation of this is that all previous vintages of capital as being available in period 
$t+1$. That is, in period $\mathrm{t}$ it is possible to produce capital at a cost of $q_{t}$, or $q_{t-1}$, or $q_{t-2}$, et cetera. However, it is clear that you would never want to build inferior capital when more efficient capital can be produced at the same cost.

It will be most interesting to study a balanced growth path for this economy. However, it should be noted that the economy, as it is presently described, may or may not exhibit balanced growth. The important ingredients for growth are listed in the following proposition.

Proposition 1. If $\theta=\left(\frac{\alpha-1}{\alpha}\right)$ then the economy exhibits balanced growth. If $\theta>\left(\frac{\alpha-1}{\alpha}\right)$ then there are decreasing returns there is a unique steady-state capital stock and the level of research knowledge. If $\theta<\left(\frac{\alpha-1}{\alpha}\right)$ then there are decreasing returns there is a unique steady-state capital stock and the level of research knowledge.

Proof: See Appendix B.

It is easy to verify that along an balanced growth path, consumption, output, real research spending, and real investment spending $\left(\Psi\left(i_{t}, V_{t}\right)\right)$ all grow at the same rate. ${ }^{7}$ This net real growth rate of output will be denoted as $g$. The gross growth rate of capital is then $(1+g)^{1 / \alpha}$. The gross "growth rate" for the price of capital (i.e. $\left.q_{t+1} / q_{t}\right)$ is then $(1+g)^{(\alpha-1) / \alpha}<(1+g)$, for $\alpha \in(0,1)$, and $g>0$.

Along a balanced growth path it is easy to show that $\phi \equiv\left(V_{t}^{\theta-1} k_{t+1}\right)$ is constant, as will $\Omega \equiv$ $V_{t} I_{t}^{-\alpha} .8$ This turns out to be synonymous with having the real value of investment, and the capital stock, as a share of aggregate output, be constant over time, which seems like an appropriate condition. The interpretation of $\phi$ is that it is proportional to how a marginal change in real research spending alters the real value of the capital stock in the next period, holding $k_{t+1}$ constant. Using equation (2.4) it is simple to check these ratios are related in the following manner

$$
\Omega^{\theta-1}=\phi\left[(1+g)^{1 / \alpha}-1+\delta\right]
$$

With this in mind, in the Technical Appendix to this paper it is shown that in the steady-state equation (2.6) can be re-written as follows:

\footnotetext{
${ }^{7}$ The fact that real investment is a constant fraction of aggregate output is well known. Also, Howitt [6] describes how research and development expenditures also appears to be a constant fraction of aggregate output, with this ratio staying between $2.2 \%$ and $2.9 \%$ since 1956 .

${ }^{8}$ In any multi-sector model of endogenous growth, the balanced growth path will display a constant ratio of the capital stocks. In the present framework such a condition takes the form of having $V_{t}^{\theta-1} k_{t+1}(\equiv \phi)$ be constant. Varying the tax rates in subsequent sections will then alter the level of this ratio.
} 


$$
(1+g)^{\sigma}=\beta\left(\left[\frac{A \alpha}{B}\right]\left[(1-\theta)+\theta(\Omega)^{\rho}\right]^{\frac{\rho-1}{\rho}}[\Omega]^{\frac{\alpha-1}{\alpha}} \phi^{\alpha-1}+(1-\delta)(1+g)^{\theta}\right)
$$

Equation (2.7) can then also be re-written in the following form

$$
(1+g)^{\sigma}=\frac{[-B \theta \beta]\left[(1-\theta)+\theta(\Omega)^{\rho}\right]^{\frac{1-\rho}{\rho}}[\Omega]^{\rho-1}}{1-\beta(1+g)^{-\sigma}} .
$$

An equilibrium then consists of a growth rate $(g)$, and constants $\phi$ and $\Omega$, satisfying equations (2.11),(2.12) and (2.13) - three equations in three unknowns.

A word of caution is in order, because although it is assumed that equations (2.6) and (2.7) will hold with equality. There is the possibility that if $\rho \in(0,1)$, that these equations (as well as $(2.9)$ and (2.10)) will hold with an inequality. This would correspond to either having no research activity take place and investment is merely in old technologies $\left(v_{t}=0\right.$, and $\left.i_{t}>0\right)$, or no new capital is created $\left(i_{t}=0\right)$, or there is so much research spending that the net cost of investment driven to zero, and therefore real investment is zero $(\Psi(\cdot, \cdot)=0)$. Although these are interesting anomalous cases, they would seem to be of rather little practical significance as it regards the behavior of observed economies. The presentation in subsequent sections will consider a few economies in which $\rho \in(0,1)$, but these other extreme instances, in which the euler equations do not hold with equality, will not be studied below. Also these cases in which either investment or research are zero presents a bit of a hurdle in studying the existence of an equilibrium since there are "corners" in equations (2.7) and (2.10) that must be considered. Although this complicates the theoretical analysis, it does not appear to produce any additional insights. Therefore, the for the sake of convenience the following proposition is stated only for the case in which investment and research spending are strictly positive.

Proposition 2. For $\rho \leq 0$, there exists a unique equilibrium growth rate for this economy.

Proof: See Appendix B.

\subsection{The $\rho=0$ case.}

The model is somewhat simpler when there is unitary elasticity of substitution between investment and research spending, or when $\rho=0 .^{9}$ This implies that the price of new investment is independent of the level of investment, and then takes the form:

\footnotetext{
${ }^{9}$ The cautious reader will note that one does not easily obtain the solutions for the $\rho=0$ case by just letting $\rho=0$ in the previous section. This is because in the euler equations there is implicitly terms involving $(\rho / \rho)$, and so L'Hopital's rule has to be applied with some care.
} 


$$
q_{t}=B V_{t}^{\theta}
$$

Also, the quantity of real investment in period $t$ is then equal to $q_{t} i_{t}=B\left(V_{t}^{\theta}\right) i_{t}\left(=\Psi\left(i_{t}, V_{t}\right)\right.$, from equation (2.3)). Furthermore, the equation determining the return to research spending is also simplified, and can be written as follows:

$$
R_{t}=-i_{t}\left(\frac{\partial q_{t}}{\partial V_{t}}\right)=-i_{t} B \theta\left(V_{t}\right)^{\theta-1}
$$

\subsection{The $\delta=1, \rho=0$ case.}

The analysis is even simpler if it is assumed that the depreciation is $100 \%$. In this case equations $(2.12)$ and (2.13) reduce to

$$
(1+g)^{\sigma}=\beta\left(\frac{A \alpha}{B}\right) \phi^{\alpha-1}=\frac{-\beta B \theta \phi}{1-\beta(1+g)^{-\sigma}}
$$

so that

$$
\phi=\left(\frac{-\theta B^{2}}{A \alpha}\right)^{\left(\frac{1}{\alpha-2}\right)}\left[1-\beta(1+g)^{-\sigma}\right]^{1 /(2-\alpha)} .
$$

This then implies the following formula for that determines the growth rate

$$
(1+g)^{\sigma}=\beta\left[(A \alpha)^{1 /(2-\alpha)}\right]\left[B^{\alpha /(\alpha-2)}\right]\left[(-\theta)^{\left(\frac{\alpha-1}{\alpha-2}\right)}\right]\left[1-\beta(1+g)^{-\sigma}\right]^{(\alpha-1) /(2-\alpha)} .
$$

Since the left side of this equation is strictly increasing in the growth rate, and the right side is decreasing, this equation will determine the unique solution for $g$. This equation becomes even simpler in the instance in which the stock of research depreciates at $100 \%$ per period $\left(V_{t+1}=v_{t}\right)$, for then

$$
(1+g)^{\sigma}=\beta\left[(A \alpha)^{1 /(2-\alpha)}\right]\left[B^{\alpha /(\alpha-2)}\right]\left[(-\theta)^{\left(\frac{\alpha-1}{\alpha-2}\right)}\right]
$$

\subsection{The $\rho \rightarrow 1$ case.}

As $\rho \rightarrow 1$, then it can be seen from equation (2.3) (or from equation (5.2) in Appendix B), that investment and research spending become close substitutes. Then, aside from an equilibrium at a corner, the same number of units of new capital can be produced with either a) increasing real investment 
spending in period $t$ by 1 unit holding the level of knowledge $\left(V_{t}\right)$ fixed, or alternatively b) increasing the level of research knowledge $\left(V_{t}\right)$ by $\left(\frac{-1}{\theta B}\right)$ units.

Loosely speaking, in this instance investment and research knowledge are close substitutes, and so the optimal behavior will be largely dictated by the cost of the inputs used to produce capital. For example, if one requires the services generated by a computer, one avenue would be to purchase Pentium personal computer. An alternative approach would be to engage in research which would produce the technology to produce the Pentium II personal computer. After the research is undertaken, the cost of producing the new (and better!) computer, could be less than that of the old Pentium machine.

Also, in this case the cost of producing another unit of new capital is independent of the level of research spending. This is seen by looking at equation (2.8) when $\rho \rightarrow 1$, as this implies that

$$
q_{t} \equiv B\left[i_{t}^{\left(\frac{\theta}{1-\theta}\right)}\right]
$$

\subsection{The $\rho \rightarrow-\infty$ case.}

As $\rho \rightarrow-\infty$, the elasticity of substitution between research spending and investment becomes zero. That is, it becomes impossible to produce new capital without increasing the amount of investment and research spending as well.

Proposition 3. As $\rho \rightarrow-\infty$, the cost function approaches

$$
\Psi\left(i_{t}, V_{t}\right)=\left\{\begin{array}{ccc}
B V & \text { if } & i^{\frac{1}{(1-\theta)}} \leq V \\
\infty & \text { if } & i^{\frac{1}{(1-\theta)}}>V
\end{array}\right.
$$

and the optimal decision for new capital construction becomes $i=V^{1 / \alpha}$.

Proof: See Appendix B.

On the margin, an increase in the amount of new capital $\left(i_{t}\right)$ does not result in more capital unless research spending is also augmented. In this case a unit of capital cannot be constructed without the additional research spending that must go along with it.

Again loosely speaking, in this instance investment and research spending are complementary capital goods. For example, one could grow a ton of corn on land with a specific amount of capital inputs. If you wish to produce more corn, you must increase the quantity of capital inputs, but you must also 
increase research inputs so as to make the quality of these inputs better. ${ }^{10}$

The distinction between research knowledge $\left(V_{t}\right)$ and investment spending might be interpreted as the difference between quality and quantity of capital goods.

\subsection{Numerical Experiments}

It will be important to see how the growth rate is influenced by changes of the parameters of the economy. The results of the experiments will depend critically on the values of the parameters. In particular, the value of the parameters $A$ and $B$ will determine such things as the equilibrium growth rate, the ratio of investment to output, and the ratio of research spending to output. In the Technical Appendix to this paper, it is shown how to reduce the equilibrium conditions of the model so that these parameters will be able to fit these objectives. It is shown that the two parameters $A$ and $B$ can be chosen so as to let the benchmark economy, without any government distortions, achieve i) an investment share of aggregate output of $25 \%$, and ii) an annual per-capita economic growth rate of 1.5\%. Since the analysis is conducted in per-capita terms, the latter growth rate seems appropriate, and also conforms with that used by Lucas [9].

The impact of a change in these parameters is fairly obvious. The growth rate is increasing in $A$, and decreasing in $B$. The impact of a change in these parameters is fairly similar for various values of $\rho$. Consider fixing the levels of the parameters $A$ and $B$, to obtain a $1.5 \%$ annual growth rate. Now consider the steady-state impact on the growth rate of a perturbation of the parameter $B$. Clearly the growth rate of the economy will be decreasing in this parameter. Figure 1 illustrates the impact of a percentage change in $B$ on the growth rate, for two different values of $\rho$. The impact of a change in $B$ on the growth rate is closer to being a linear relationship for lower values of $\rho$. This is the instance in which there is less substitutability between research spending and investment spending. Of course, for higher values of $\rho$, there are greater opportunities for substitutability along this margin, and so the more curvature is apparent in the relationship in the Figure.

As the parameter $B$ increases, the lower is the return or marginal product from engaging in research spending. Therefore, less of this spending will be undertaken relative to investment spending. Obviously this lowers the growth rate of the economy. But also, for higher values of $\rho$, this effect is partially mitigated by increased substitution of investment spending for research spending.

\footnotetext{
${ }^{10}$ For example, it might be necessary to engage in research so as to invent better herbicides, without which more corn could not be grown.
} 


\section{A Model With Taxes}

It is appropriate to analyze a version of the model with taxes. In this case, the preferences are still given by equation (2.1). Let $\tau_{k}, \tau_{i}$, and $\tau_{r}$ denote the tax rate on capital, the investment tax credit, and the subsidy to research, respectively. The budget constraint for the individual now looks like the following:

$$
c_{t}+i_{t} \mathbf{q}_{t}\left(1-\tau_{i}\right)+v_{t}\left(1-\tau_{r}\right) \leq y_{t}=k_{t}\left[\mathbf{r}_{t}\left(1-\tau_{k}\right)+\mathbf{q}_{t-1} \boldsymbol{\delta} \tau_{k}\right]+V_{t} \mathbf{R}_{t}\left(1-\tau_{i}\right)+\mathbf{w}_{t}+\mathbf{g}_{t} .
$$

The relationship between this constraint, and the profit-maximizing behavior of firms, is detailed in

Appendix C. Here $\mathbf{r}_{t}$ is the marginal product of capital, which in equilibrium equals $\left(A \alpha k_{t}^{\alpha-1}\right)$. Also, $\mathbf{w}_{t}$ should be interpreted as non-capital income which is calculated from output remaining after capital is paid its marginal product. Additionally, $\mathbf{g}_{t}$ is the lump-sum payment given by the government to agents. In a competitive equilibrium the tax or subsidy parameters, together with the terms in bold print should be interpreted as parameters from the agent's perspective. The right side also contains the return or imputed value from the stock of research knowledge. It must be included since any resources devoted to research spending must have the resulting return included on the right side of the budget constraint. Since investment is possibly subject to an investment tax credit, the net return to research is written as $\mathbf{r}_{t}\left(1-\tau_{i}\right)$.

Here the capital letters denote the equilibrium values for variables. As before, the price of a unit of new capital is denoted as

$$
q_{t} \equiv B\left[i_{t}^{\left(\frac{\rho}{1-\theta}\right)-1}\right]\left[(1-\theta) i_{t}^{\frac{\rho}{(1-\theta)}}+\theta\left(V_{t}\right)^{\rho}\right]^{(1 / \rho)-1} .
$$

Here, $i_{t}$ and $V_{t}$ are evaluated at their equilibrium values.

To focus on the effect of distortional taxes on the behavior of the economy, it will be convenient to let all the government revenue derived from these taxes be given back to agents in the form of a lump-sum transfer $\left(g_{t}\right)$. Again, the capital evolution equation is given by equation (2.4).

Now the counterparts to the optimization conditions, as characterized by equations (2.9) and (2.10), are given by the following:

$$
q_{t}\left(1-\tau_{i}\right)\left(c_{t}\right)^{-\sigma}=\beta\left(c_{t+1}\right)^{-\sigma}\left[r_{t+1}\left(1-\tau_{k}\right)+\left(\tau_{k} \delta q_{t}\right)+(1-\delta)\left(1-\tau_{i}\right) q_{t+1}\right]
$$


and

$$
\left(1-\tau_{r}\right)\left(c_{t}\right)^{-\sigma}=\sum_{j=1}^{\infty} \beta^{j}\left(c_{t+j}\right)^{-\sigma} R_{t+j}\left(1-\tau_{i}\right) .
$$

Equation (3.2) says that the cost of a unit of investment is lowered by the amount of the investment tax credit $\left(1-\tau_{i}\right)$, as is the real value of capital left over after depreciation. Similarly the return to capital is lowered by the amount of the capital tax rate.

Equation (3.3) says that the cost of a undertaking investment spending is reduced by the amount of the research spending subsidy $\left(1-\tau_{r}\right)$. The research subsidy $\left(\tau_{r}\right)$ implicitly lowers the left side of equation (3.3), and therefore lowers the cost (or raises the return) of undertaking research spending. On the other hand, the investment tax credit lowers the right side of this same equation, and therefore lowers the return of research spending. What is going on there, is that the investment tax credit and the research tax credit should be looked upon as competitors for the same resources. The investment tax credit reduces the incentive to engage in research spending, because it encourages investment of resources in "old" technologies. The research subsidy does the opposite: it encourages the development of new technologies, and less investment in old ones.

There is another new issue concerning taxes that can be illustrated in this framework. It is well known that an arbitrarily high capital tax, when accompanied by a prudently chosen investment tax credit, results in no distortion to the capital accumulation decision. This can be seen by noting the fact that the capital tax will lower the value of the return to capital (the right side of equation (3.2)), but the investment tax credit will then counteract this effect by lowering the cost (the left side of equation (3.2)). When these rates are judiciously chosen, these two companion policies really amount to a tax on the return to existing capital, while leaving new or future capital untaxed. Now in the present framework things are not quite so simple. It is still true that a hefty capital tax, when accompanied by a specific investment tax credit, will result in no distortion to the capital accumulation decision (again as seen by equation (3.2)). However, these policies will then distort the research spending decision by lowering the return to undertaking research spending (i.e. the right side of equation (3.3) is lowered). That is, the investment tax credit encourages the production of "old types of capital," and reduces the incentive to engage in research spending, which results in development of newer types of capital. The effect of an investment tax credit can be offset by a research subsidy the same size of the investment tax credit $\left(\tau_{r}=\tau_{i}\right)$ so as to leave the left and right sides of equation (3.3) undistorted. In this context there are two decisions that must be made by the agent, and this shows that it is possible to impose a 
capital tax, but yet design policies so that neither decision is distorted in the end.

It may be illustrating to consider what happens to equation (3.3) as $\rho \rightarrow 1$. It is possible to see that this equation takes the following form

$$
\left(1-\tau_{r}\right)\left(c_{t}\right)^{-\sigma}=\sum_{i=1}^{\infty} \beta^{i}\left(c_{t+i}\right)^{-\sigma}\left(1-\tau_{i}\right)(-B \theta) .
$$

In other words, the growth rate of the economy is determined from this equation as

$$
(1+g)^{\sigma}=\left(\frac{-\beta B \theta\left(1-\tau_{i}\right)}{\left[1-\beta(1+g)^{-\sigma}\right]\left[1-\tau_{r}\right]}\right)
$$

Now this growth rate is increasing in the size of the research subsidy $\left(\tau_{r}\right)$, but independent of the capital tax rate $\left(\tau_{k}\right)$. The reason for this is that since real investment spending, and research spending are close substitutes (because $\rho \rightarrow 1$ ). Now a word of caution is in order for this example, since as $\rho \rightarrow 1$, agents will then choose either to undertake research spending, but little investment $\left(v_{t}>0, \Psi(\cdot, \cdot) \approx 0\right)$, or no research spending, but plenty of investment $\left(v_{t} \approx 0, \Psi(\cdot, \cdot)>0\right)$. In the former case, the growth rate of the economy will be strongly influenced by the size of the research subsidy $\left(\tau_{r}\right)$, but in the latter case it will be influenced by the size of the capital tax rate $\left(\tau_{k}\right)$. In the latter case the growth rate may not be substantially influenced by the research subsidy since little research is being undertaken.

The instance in which there is little research spending, but plenty of investment could be thought of as a case in which new vintages of capital are rarely discovered, and instead growth takes place through investing in existing technologies. Alternatively, the opposite instance, if there is a large level of research but a rather low quantity of new capital construction, then there are frequently new technologies invented, but little investment in each one, since yet another new one is just about to be invented. In any case, perhaps one should not put too much empirical weight on the behavior of the case where $\rho \longrightarrow 1$, because it is very unusual to observe such "wild" behavior of investment or research spending.

With this in mind, it is not surprising that the effect of a change in the capital tax rate would depend on the degree of substitutability between research and investment (as measured by $1 /(1-\rho)$ ).

Next, after some tedious algebra, for the model with government taxation, the counterpart to equations (2.12) and (2.13) are the following 


$$
(1+g)^{\sigma}=\beta\left[\begin{array}{c}
\left(\frac{A \alpha}{B}\right)\left(\frac{1-\tau_{k}}{1-\tau_{i}}\right) \phi^{\alpha-1} \Omega^{\frac{\alpha-1}{\alpha}}\left[(1-\theta)+\theta \Omega^{\rho}\right]^{1-1 / \rho}+ \\
(1-\delta)(1+g)^{\theta}+\left(\frac{\tau_{k} \delta}{1-\tau_{i}}\right)
\end{array}\right]
$$

and

$$
(1+g)^{\sigma}=\frac{\beta(-B \theta)\left(\frac{1-\tau_{i}}{1-\tau_{r}}\right) \Omega^{\rho-1}\left[(1-\theta)+\theta \Omega^{\rho}\right]^{1 / \rho-1}}{1-\beta(1+g)^{-\sigma}}
$$

where

$$
\Omega=\phi^{-\alpha}(1+g)\left[(1+g)^{1 / \alpha}-(1-\delta)\right]^{-\alpha}
$$

where $\Omega$ and $\phi$ are defined as in Section 2.1. With this in mind, equations (3.4), (3.5) and (3.6) are then three equations in three unknowns: $\Omega, \phi$, and $g$. (The Technical Appendix, which is available upon request, derives these equations.)

Also, this framework also gives us an opportunity to compare the impacts of a tax on capital, an investment tax credit, and a research subsidy. Most models are unable to give quantitative comparisons between the effects of these three parameters. For example, within the context of most versions of neoclassical growth models, it is possible to fashion a combination of a tax on capital, and an investment tax credit which achieve the optimal growth rate, or the optimal accumulation path for capital. Hence it is not clear at the outset how a research subsidy enters into this sort of discussion, despite one's inclination that it must be important. It might be cheaper to employ a research subsidy, rather than an investment tax credit to address these distortions imposed by capital taxation.

\subsection{Numerical Results}

It is illuminating to see how the growth of this economy changes as the tax rate is altered, for various values of $\rho$. Later the analysis will focus on the case in which $\tau_{r}=\tau_{k}$, which implies that research spending and investment are both financed out of retained earnings. If, in addition, there is yet another research subsidy then the value of $\tau_{r}$ will be even higher.

\subsection{Research Subsidy or Investment Tax Credit?}

Consider a government that is able to use its policy tools in order to raise the growth rate. What would be the best (or cheapest) method to attain this goal? In particular, would it be more efficacious 
to employ a subsidy (or tax credit) to research activity, or instead use a subsidy for investment? The present model provides a mechanism through which this comparison can be conveniently conducted.

In this analysis a period will be interpreted as a year, so the following parameter values seem appropriate: $\beta=.96, \alpha=.35, \sigma=2.0$ and $\delta=.08$. The remainder of the paper will utilize these parameter values. These are values are similar to those used by Lucas [9], and this will facilitate a comparison between the results of the two papers. Then the values of $A$ and $B$, are chosen to produce a growth rate of $1.5 \%$, an investment to output ratio of $25 \%$. Figure 2 shows how the growth rate changes as a function of the subsidy rate (or tax credit rate) of investment or research activity for two different values of $\rho$. As can be seen, for a given rate of subsidy, a larger impact on the growth rate can be had by applying the subsidy to research spending, rather than investment. That is, the growth affects of a research subsidy are approximately twice as large as the effects of an investment subsidy. What this means is that it would take an investment tax credit of about $10 \%$ to generate the same increase in the growth rate as could be accomplished by a research subsidy of $5.0 \%$. However, this comparison is even more stark when one realizes that the actual volume of investment is considerably larger than that of research spending, so that the actual amount of the subsidy would be considerably less in the case of the research subsidy.

The same Figure shows this same effect of a research or investment subsidy for $\rho=0.3$, and $\rho=-20$. In the case of the research subsidy, the effect on the growth rate of the research subsidy is virtually the same for all values of $\rho$, though the effects are slightly greater for higher values of $\rho$. For higher values of $\rho$ (i.e. closer to 1.0) research spending and new capital construction can be viewed as close substitutes, whereas for larger negative values of $\rho$ they could be viewed more as complements. Both the research subsidy and the investment tax credit have a more pronounced impact on the growth rate for higher values of $\rho$. The reason for this is that if research and investment are close substitutes $(\rho=0.3)$, then a subsidy to either research or investment allows more resources to be pulled out of the other (non-subsidized) activity, and instead used for the subsidized activity. When research and investment are more complementary $(\rho=-20.0)$, then a subsidy to, say, research, means that it is advantageous to devote resources to this activity, but this is only worthwhile if more new capital is produced as well. Hence the growth impact of such a subsidy is likely to substantially mitigated in this instance. 


\subsection{Growth and Capital Taxation}

Since there are no externalities or increasing returns in the model, the equilibrium without any government intervention delivers optimal allocations. Nevertheless, it is important to study the impact that government policies can have on the growth rate.

In these experiments different economies are studied that are parameterized by different values of $\rho$, but keeping the following parameters at their values: $\alpha=.35, \beta=.96, \sigma=2.0$ and $\delta=.08$. To facilitate the comparison among these economies, for each of these values of $\rho$, the parameters $A$, and $B$, are chosen so that the growth rate of the benchmark economy is $1.5 \%$ when the capital tax rate is zero. Here it is assumed that $\tau_{r}=\tau_{k}$, so that research spending is tax-deductible to the firm.

Given this, Figure 3 shows that the growth rate of the economy can be increasing in the rate of capital taxation. The reason for this is as follows. A rise in the tax rate of capital obviously lowers the return to producing more capital. However, since research spending is tax-deductible, the presence of the tax makes it more advantageous to attempt to reduce the cost of capital accumulation through research spending, rather than through new capital construction. That is, an increase in the capital tax rate causes there to be a shift from "quantity-to-quality" when accumulating capital. As can be seen in the diagram, if research spending and investment spending are close substitutes (high values of $\rho)$, then this effect can be quite pronounced.

The ' $\cap$-shaped' nature of the diagram in Figure 3 suggests that it may be possible to have two otherwise identical economies but where one has a much higher capital tax rate, and these economies could nevertheless grow at the same rate. Consequently these economies would have the same after-tax return to capital (or equilibrium interest rate) as well. This is not to say that they would necessarily have the same standard of living, or level of consumption.

For reference, the solid line labeled 'A-K' in the diagram shows how the growth rate in the 'A-K' model would be affected by a change in the capital tax rate. ${ }^{11}$ As mentioned above, this is just a suitably parameterized version of the benchmark model with $\alpha=1$. Not surprisingly, this is a downward sloping line. It is notable however, that the impact of a change in the capital tax rate is quite different in this model, and the one in which research spending plays such a prominent role $(\alpha \in(0,1))$. Furthermore, it is interesting to see how much more punitive capital taxation can be in the 'A-K' framework, than in the model studied in this paper. In the 'A-K' model it would only require a tax rate of approximately

\footnotetext{
${ }^{11}$ Care has been taken here to insure that it is the net return to capital (i.e. not gross) that is being taxed in all of these examples.
} 
$9 \%$ to reduce the growth rate from $1.5 \%$ to $1.2 \%$. In the model of this paper, if $\rho=-20$, to accomplish such a reduction in the growth rate would require a tax rate in excess of $50 \%$ ! If $\rho$ were to assume a higher value, then it would require an even larger tax rate.

\subsection{Welfare Costs}

It is then of interest to calculate the welfare costs of capital taxation within this framework. Consider the following experiment. Suppose the tax and subsidy rates are zero, and the economy is on its balanced growth path. The model parameters are set so that this growth rate is $1.5 \%$ per period. Now consider increasing the capital tax rate to $35 \%$ forever, but rebating the resulting revenue to agents in a lump-sum manner. Consider measuring the welfare cost of such a policy by the amount that the agent's consumption stream would have to be raised, measured in percent, along the new growth path to obtain the same level of discounted utility as he would have attained while consuming along the old growth path.

Consider the case in which $\rho=-20$, so that there is little opportunity for substitution between research spending and new capital construction. Even in this instance the welfare cost of imposing a tax increasing the tax rate from zero to $35 \%$ would be $0.1 \%$ of steady-state consumption. This is a relatively trivial amount.

By comparison, Lucas [9] makes a similar calculation for a model without growth, and finds that the welfare costs of a $35 \%$ tax rate are approximately $7 \%$ of steady-state consumption and approximately $1 \%$ of consumption when the transition is taken into account. It is relatively simple to make this calculation for the A-K version of the model $(\alpha=1)$, in which the model parameter $A$ is calculated to deliver a $1.5 \%$ annual growth rate with a zero tax rate. In this case the welfare cost of raising the tax rate from zero to $35 \%$ would be $4.9 \%$ of steady-state consumption. By comparison, these are substantially larger costs than those obtained in the benchmark version of the model under study here. These results may help explain why there is not a more-strongly voiced desire for a reduction in capital tax rates, despite the perception that the benefits would be so immense: perhaps the benefits of this type of tax reform would not be so considerable after all.

It is also of interest to note that the effect of an unexpected raising of the tax rate in this framework is different from that what one would expect in the usual model studied by Lucas, or in the A-K framework. In both of these latter cases, an unexpected rise in the tax rate would result in a sudden increase in consumption because investment and saving would fall. This rise in consumption is more 
than offset, in welfare terms, by the lower future path of consumption. In the case of the present model, something close to the opposite takes place. A sudden rise in the tax rate means that there is a sudden fall in consumption, while the agent engages in a burst of research activity. This increased research activity either slightly raises the future growth rate, or prevents any substantial fall in the growth rate of output. In any case, the initial fall in consumption results in a reduction of welfare, and this can be only partially offset if there is a rise in the future growth rate.

\subsection{A Growth Maximizing Tax Rate}

In light of the results just described, it is then of interest to inquire about the rate of capital taxation that maximizes the growth rate. In particular, it is of interest to see how the growth-maximizing tax rate changes as the parameter $\rho$ changes. To take this experiment seriously, it may be useful to consider a slightly different parameterization.

Again let us consider different economies parameterized by different values of $\rho$. However, this time for each of these values of $\rho$, the parameters $A$, and $B$, are chosen so that the growth rate of the economy is $1.5 \%$ when the capital tax rate is $30 \%$.

Figure 4 shows how the growth rate changes as the capital tax rate changes, for various values of $\rho{ }^{12}$ By construction, each of these economies have a growth rate of $1.5 \%$ for a capital tax rate of $30 \%$. The first thing to note from this diagram is that for many of these economies, the growth rate of the economy is relatively unresponsive to changes in the capital tax rate. For the case where $\rho=-.5$, as the capital tax rate is raised from zero to $20 \%$, there is very little change in the growth rate. Furthermore, for all values of $\rho$ the growth rate is a concave function of the tax rate.

Figure 4 also shows how the growth-maximizing tax rate is not necessarily zero, and changes as a function of the parameter $\rho$. For values of $\rho$ that are greater than -.10, the growth rate maximizing tax rate is zero. But for lower values of $\rho$, then the growth rate maximizing tax rate begins to be positive. In fact, tax rate that maximizes the growth rate turns out to be an decreasing function of $\rho$. For example, for $\rho=-20$, the tax rate that maximizes the growth rate is approximately $16 \%{ }^{13}$

\footnotetext{
${ }^{12}$ The shapes of these curves are slightly different than those shown in Figure 3 because different values have been chosen for the parameters $A$ and $B$.

${ }^{13}$ At this point it is important to compare these results with those of Aiyagari [1]. Though both papers appear to find that there are beneficial reasons for imposing a capital income tax, the papers have little to do with each other. Aiyagari shows that, due to the presence of idiosyncratic risk, agents may overaccumulate capital, and therefore a capital tax may deter such accumulation, and would therefore be optimal. At this point in the present framework, it has been shown that capital taxation may raise the growth rate, but such a policy would not be optimal. However, in the next section it is shown that there may be circumstances under which a capital tax may be beneficial.
} 
In the economies illustrated in Figure 3, the tax rate that maximizes the growth rate is also positive. For these examples, the higher is the value of the parameter $\rho$, the higher is the tax rate that maximizes the growth rate.

\subsection{Externalities}

There are a plethora of growth models that rely on externalities to generate growth. For example, Romer [11] considers a model in which there can be growth because there is an externality whereby agents benefit from their own capital, but also from the capital stock of others. In such an environment, it can be beneficial to have a subsidy to capital accumulation to facilitate the attainment of the optimal capital stock level and the optimal growth rate. The obvious question here then is: What would be the appropriate policy if such an externality were present in this model?

Suppose that the production function in equation (2.2) is now given as follows: $A k_{t}^{\alpha} K_{t}^{\omega}$, where $\omega>0$ is a measure of the amount of the externality, and $K_{t}$ is the average capital stock in the economy. Now clearly it is desirable to encourage the accumulation of capital, but as described above, there are several ways to accomplish this task. One would be an investment tax credit. This would encourage the accumulation of "old vintages" of capital. However, within the context of the present environment it is not so clear as to what would be the effect of capital taxes or investment subsidies. Capital taxes can encourage research spending which then result in higher future capital stocks.

However, there are other externalities that can be considered. Many researchers would subscribe to the view that there are strong externalities present in research activities, rather than merely in the production process. That is, this could explain why it is possible to witness the agglomeration of scientists or academics, presumably because they benefit from the professional interaction with other researchers. This raises the question of whether it would be more desirable to encourage or subsidize production, or capital accumulation, or alternatively to subsidize the research activity. Most growth models are reticent on this issue since they do not have any such separate activities, but the present model is ideal for analyzing this question, since there is a dichotomy between research and production.

Suppose that instead of the function $\Psi(\cdot, \cdot)$ as being given by equation $(2.3)$, that it is instead given as follows:

$$
\Psi\left(i_{t}, V_{t} ; \hat{V}_{t}\right)=B\left[(1-\theta) i_{t}^{\frac{\rho}{(1-\theta)}}+\theta\left(V_{t}\right)^{\rho}+\gamma\left(\hat{V}_{t}\right)^{\rho}\right]^{1 / \rho} .
$$

Here $V_{t}$ represents the individual's quantity of research spending, while $\hat{V}_{t}$ is the average amount of 
research spending in the economy. ${ }^{14}$ Since this is a representative agent economy, these quantities will be equal in an equilibrium. The agent would obviously choose the former quantity, while taking the latter quantity as given. In this case if $\gamma<0$, the agent would benefit from having other agents engage in research spending because this aggregate spending would reduce the cost of each agent's capital accumulation. This is indeed a positive externality, because each agent would benefit from reduced costs generated from the research activity of others. Now in this environment it is clear that it would be beneficial to get agents to raise the level of research spending. One way to accomplish this would again be to levy of a capital tax. This would make research spending more desirable relative to new capital construction $\left(i_{t}\right)$, because research spending is tax-deductible. That is, it would encourage the development of new technologies, as opposed to investment in old technologies. Therefore, such a tax would help the economy potentially achieve a more desirable level of research spending, relative the level of new capital construction.

It is then of interest to find the capital tax rate $\left(\tau_{k}\right)$ that achieves the optimal growth rate for this economy. Note that this does not mean achieving the highest growth rate, but instead the growth rate that would solve the relevant social planning problem. It is important to note that there may not be a unique value of the capital tax rate $\left(\tau_{k}\right)$ that generates the optimal average growth rate. As Figures 3 and 4 show, due to the " $\cap$-shaped" nature of these relationships, it may be the case that a given growth rate can be achieved with one or two distinct capital tax rates. Alternatively, it can also be that there does not exist any tax rate alone that can achieve the optimal growth rate.

Figures 5 and 6 illustrate the tax rates that produce the optimal growth rate, for values of $\rho=.10$ and $\rho=-2.0$, respectively. Again, for each of these diagrams the values of the parameters $A$ and $B$ are set so that the equilibrium growth rate for the economy is $1.5 \%$, when $\gamma=0$. The horizontal axis is intended to measure the magnitude of the research externality, and so the units are the ratio of the parameters $(\gamma / \theta)$.

Figure 5 displays the case in which $\rho=.10$. In this Figures, for values of $(\gamma / \theta)$ below 0.22 , there are two distinct tax rates that produce the socially optimal growth rate. It is important, first of all, to notice that the scale on the horizontal axis is such that only "small" values of the externality are being considered. In this diagram, the "branch" of diagram with the ' $\bigcirc$ ' symbol shows how the desired growth rate can be attained with a "low" capital tax rate. The branch with the ' $\square$ ' symbol will also attain the desired growth rate, given the externality, but will do so with a considerably higher tax rate.

\footnotetext{
${ }^{14}$ The condition for balanced growth here is $\theta=-\gamma+(\alpha-1) / \alpha$.
} 
The reason is that by taxing capital at so high a rate, it causes there to be too high a ratio of research to capital stock. In a sense, along this branch there is too much research activity being undertaken. For values of $(\gamma / \theta)$ above 0.22 , it is not possible to impose any capital tax alone, in order to generate the relevant growth rate. However, what is shown in the diagram is the unique tax rate that maximizes the growth rate for that level of the externality, and thereby comes the closest to the socially optimal growth rate. For values of the externality in this range, to attain the socially optimal growth rate it will be necessary to do something more to subsidize research, such as give it a direct research subsidy.

Figure 6 shows this same relationship for $\rho=-3.0$. It has the same general features as Figure 5, with capital taxation being desirable for moderate values of the externality parameter. A close examination of the axis reveals that capital taxation can help to support the optimal growth rate for much larger values of the externality in the $\rho=.10$ case. The reason is that capital taxation has its impact in this model by causing there to be substitution between investment and research spending. In the case where $\rho=-3.0$, there is much less latitude for this substitution, and so taxation cannot have as much of an impact, given the size of the externality.

What is going on here is the following. Because of the externality in research, in an undistorted private optimum there will not enough research being undertaken by agents to achieve the social optimum. That is, agents will not be devoting enough resources to the development of new technologies, and instead will be devoting resources to investing in existing technologies. The latter activity means just adding to the capital stock so that output in the near future will be increased, but the former activity means producing a new technology which would add to output in the more distant future. The only way to correct for this externality is to somehow discourage agents from investing in existing technologies, and instead get them to spend resources on the development of new technologies. One way to accomplish this is by imposing a research subsidy. But another method would be to levy a capital tax, because this discourages the investment in old capital, and encourages research spending which facilitates the development of new technologies. Agents will then substitute away from new capital construction, and instead undertake more research spending.

There is one simple case to consider. Consider the example described in section 2.3 above, in which $\rho=0$, and $\delta=1$, but where research knowledge depreciates at $100 \%$ per period (i.e. $V_{t+1}=v_{t}$ ). Assume that the externality is still of the type described by equation (3.7). If the capital tax is levied net of depreciation then it is possible to show that the growth rate is increasing in the tax rate, in a neighborhood of $\tau_{k}=0$, if the following condition is satisfied: $\beta>\alpha(1+g)^{\sigma}$. This is also the condition 
that must be satisfied for a positive capital tax to deliver the optimal growth rate in the presence of the externality.

\section{Final Remarks}

The goal of this paper is to investigate the link between research spending and investment, and the substitution possibilities between theses two activities, within the context of a relatively traditional endogenous growth model. The model also shows how research spending influences the relative price of new capital. In this sense, this article is a step in the direction of uniting the considerable literature on endogenous growth, with the findings of Greenwood, Hercowitz, and Krusell [4], that investmentspecific technological change is a considerable force in explaining the observed growth rates.

The findings of this paper suggests that a complete analysis of the impact of capital taxation cannot be divorced from the issue of how technological change is generated. If technological change is generated exogenously, then the impact of capital taxation is likely to be quite different from that found in this paper. Furthermore, if technological change is generated through a positive externality in production, then capital taxation would seem to have still a different impact yet.

It has been shown that higher capital tax rates do not necessarily have a negative impact on the growth rate of an economy, and that the welfare costs of capital taxation may be negligible. As such this paper provides more insight as to why it may be that capital tax rates to not appear to be a major determinant of growth rates across countries. Even simple tax policies can have a complicated impact on an economy, depending on the nature of the technology. To be more certain about the impact of capital taxes on the growth rate, it appears necessary to study the substitution opportunities, not just between capital and labor, but between different types of capital, and certainly between capital and research activity. It is not enough to know how investment will respond to government-imposed distortions, but it is critical to be able to evaluate how research spending will change because of these policies as well.

A natural question to ask would be how the incorporation of human capital would alter this model,

and whether it would overturn many of the results listed above. A precise answer to this question cannot be delivered without an explicit characterization of a model, but it seems that many of these results are likely to be robust to the incorporation of human capital. The reason is as follows. What is important in the model studied in this paper is that it is possible to engage in some substitution between two inputs: namely capital and research spending. If human capital were incorporated, then 
there would be more - not less - opportunity for substitution between the production inputs. Hence an increased capital tax would then motivate agents to substitute research spending and human capital for the capital input, and therefore ameliorate the impact of the tax.

Furthermore, it would seem that it may be impossible to disentangle the effects on the growth rate attributable to increased human capital (however this is measured) as opposed to the effect from the introduction of newer types of capital. To illustrate this, consider the following example. A software engineer may be said to have a greater amount of human capital than engineers of previous generations, and be paid accordingly. On the other hand, this engineer can only be this productive if there are newer and better computers that he can utilize. In the absence of theses computers, his human capital would have considerably less value. On the other hand, the newer faster computers themselves would have little value without the skills possessed by people like the engineer who may know how to make use of them. Some types of new capital require new types of labor to make them productive. Once it is acknowledged that there are newer vintages of capital, it is not clear how much of the increased productivity to ascribe to the capital, and how much to the labor. Viewed from this perspective, it is not clear that adding human capital to the present model would really represent a net contribution (as opposed to merely a substitution).

There is also a positive question that is paper attempts to address. Namely, within the context of many conventional models capital taxation appears to have severe dramatic welfare costs, and so it is puzzling as to why such high tax rates on capital are observed. The present paper suggests that observed levels of capital taxation may not have that dramatic a welfare cost, and if there are research externalities it may be that sizeable capital taxes may be desirable.

\section{Appendix A}

Another interpretation of the model is to re-write the resource constraint (2.2) as follows

$$
c_{t}+v_{t}+\tilde{\imath}_{t} \leq y_{t}=A k_{t}^{\alpha}
$$

Here $\tilde{\imath}_{t}$ is the real value (i.e. measured in units of the consumption good) of investment. The equation describing the cost function (equation 2.3) can be "inverted" ( since $\tilde{\imath}_{t}=\Psi\left(i_{t}, V_{t}\right)$ ), and substituted into the capital evolution equation (2.4) to yield 


$$
k_{t+1}=(1-\delta) k_{t}+\left[\left(\frac{1}{1-\theta}\right)\left(\frac{\tilde{t}_{t}}{B}\right)^{\rho}-\left(\frac{\theta}{1-\theta}\right)\left(V_{t}\right)^{\rho}\right]^{\left(\frac{1-\theta}{\rho}\right)}
$$

Again, the last term on the right side of equation (5.2) could be interpreted as a production function that produces new capital, and takes real investment and the stock of research knowledge as inputs. In contrast, the corresponding term $(\Psi(\cdot, \cdot))$ in of equation $(2.2)$ could be interpreted as a cost function for the production of investment goods. Of course, since $\theta<0$, this technology is increasing in both arguments. The last equation also makes it apparent that $\rho$ should be interpreted as the elasticity of substitution between real investment, and the stock of research knowledge. As $\rho \rightarrow 1$, this equation becomes

$$
k_{t+1}=(1-\delta) k_{t}+\left[\left(\frac{1}{1-\theta}\right)\left(\frac{\tilde{x}_{t}}{B}\right)-\left(\frac{\theta}{1-\theta}\right)\left(V_{t}\right)\right]^{1-\theta}
$$

That is, there is an infinite elasticity of substitution between investment and research spending.

Alternatively,as $\rho \rightarrow-\infty$, equation (5.2) becomes

$$
k_{t+1}=(1-\delta) k_{t}+\min \left[\left(\frac{\tilde{u}_{t}}{B}\right), V_{t}\right]^{1-\theta} .
$$

Of course, this equation implies that in an equilibrium, if one were to increase $\tilde{\imath}_{t}$ by one unit, this would not result in any increase in the capital stock unless the stock of research knowledge were also increased. In other words, there is an added cost to augmenting the capital stock beyond just increasing $\tilde{\imath}_{t}$.

\section{Appendix B}

Proof of Proposition 1:

The potential for balanced growth hinges on whether equations (2.2), (2.3), (2.4) and (2.5) are jointly homogeneous of degree one in the following vector of variables: $\left[c_{t}, v_{t}, V_{t}, i_{t}^{1 / \alpha}, k_{t}^{1 / \alpha}\right]$. However, by substituting equations (2.3), (2.4), (2.5) into equation (2.2), it should be clear that this homogeneity is present if and only if, the function $\Psi(\cdot, \cdot)$ jointly homogeneous of degree one in $V_{t}$ and $i_{t}^{1 / \alpha}$. But this is true if and only if $\theta=\frac{\alpha-1}{\alpha}$.

If $\theta>\frac{\alpha-1}{\alpha}$, then it is easy to check that the function $\Psi(\cdot, \cdot)$, from equation $(2.3)$, is homogeneous of a degree greater than one jointly in $V_{t}$ and $i_{t}^{1 / \alpha}$. This implies that the cost function for investment is increasing more than proportionately in the two inputs. Balanced positive growth is not possible in 
this instance because eventually the cost of investment would exceed aggregate output. The economy must then converge to a constant steady-state with no growth.

Similarly, if $\theta<\frac{\alpha-1}{\alpha}$, then the function $\Psi(\cdot, \cdot)$, is homogeneous of a degree less than one jointly in $V_{t}$ and $i_{t}^{1 / \alpha}$. This implies that the cost function for investment increases less than proportionately in the two inputs. A balanced growth rate is not possible because the cost of investment is falling to zero. Hence the growth rate for the economy will must increasing over time. $\square$

\section{Proof of Proposition 2:}

The relevant equilibrium conditions are written as follows (once a substitution has been made to remove $\phi$, using equation (2.11))

$$
(1+g)^{\sigma}=\beta\left(\begin{array}{c}
{\left[\frac{A \alpha}{B}\right]\left[(1-\theta)+\theta(\Omega)^{\rho}\right]^{\frac{\rho-1}{\rho}}(1+g)^{\theta}\left[(1+g)^{1 / \alpha}-1+\delta\right]^{1-\alpha}} \\
+(1-\delta)(1+g)^{\theta}
\end{array}\right)
$$

and

$$
(1+g)^{\sigma}=\beta+[-B \theta \beta]\left[(1-\theta)+\theta(\Omega)^{\rho}\right]^{\frac{1-\rho}{\rho}}[\Omega]^{\rho-1} .
$$

It is straightforward to establish that since $\theta<0$, the right side of equation (6.1) is increasing in $\Omega$. Also, as $\Omega \rightarrow(1-\alpha)^{-1 / \rho}$, the right side of $(6.1) \rightarrow \beta(1-\delta)(1+g)^{\theta}$, whereas as $\Omega \rightarrow+\infty$, the right side of this equation $\rightarrow \infty$. Obviously, the left side of this equation is increasing from 0 to $\infty$ in $g$, while the right side of equation (6.1) is decreasing in $g$. Therefore, this implies that there is a continuous increasing function $\Omega_{1}(g)$, which satisfies equation (6.1).

Similarly, it is also possible to establish that the right side of equation (6.2) is decreasing in $\Omega$, while again the left side is increasing in the growth rate $g$. Furthermore, as $\Omega \rightarrow(1-\alpha)^{-1 / \rho}$, the right side of $(6.2) \rightarrow \infty$, whereas as $\Omega \rightarrow+\infty$, the right side of this equation $\rightarrow \beta$. Therefore, this implies that there is a continuous increasing function $\Omega_{2}(g)$, that satisfies equation (6.2).

In summary then, the function $\Omega_{1}(g)$ is an increasing continuous function that maps the interval $\left[[\beta(1-\delta)]^{1 /(\sigma-\theta)}-1, \infty\right]$ into the interval $\left[(1-\alpha)^{-1 / \rho}, \infty\right]$. The function $\Omega_{2}(g)$ is a decreasing continuous function and maps the interval $[\beta-1, \infty]$ into $\left[(1-\alpha)^{-1 / \rho}, \infty\right]$. Hence there must exist a unique value $g^{*}$ such that $\Omega_{1}\left(g^{*}\right)=\Omega_{2}\left(g^{*}\right)$, and hence the right sides of equation (6.1) and (6.2) are equal, since the left sides of these equations are equal.

The reasoning for the case of $\rho=0$, follows similarly, but is especially simple because equations (6.1) and (6.2) take on a much simpler form. 


\section{Proof of Proposition 3:}

For convenience of notation, define $x \equiv i^{\frac{1}{(1-\theta)}}$. Then note that the following:

$$
\begin{gathered}
\Psi\left(i_{t}, V_{t}\right)=\Gamma(x, V) \equiv B\left[(1-\theta) x^{\rho}+\theta(V)^{\rho}\right]^{1 / \rho} \\
\Gamma_{1}(x, V) \equiv B(1-\theta)\left(x^{\rho-1}\right)\left(\frac{\Gamma}{B}\right)^{1-\rho} \\
\Gamma_{2}(x, V) \equiv B \theta\left(V^{\rho-1}\right)\left(\frac{\Gamma}{B}\right)^{1-\rho}
\end{gathered}
$$

Then it is easy to see that

$$
\frac{\Gamma_{1}(x, V)}{\Gamma_{2}(x, V)}=\frac{(1-\theta)}{\theta}\left(\frac{x}{V}\right)^{\rho-1}
$$

Now consider that as $\rho \rightarrow-\infty$

$$
\frac{\Gamma_{1}}{\Gamma_{2}} \rightarrow\left\{\begin{array}{c}
0 \text { if } \quad x>V \\
\frac{(1-\theta)}{\theta} \text { if } \quad x=V \\
-\infty \text { if } \quad x<V
\end{array}\right.
$$

This is illustrated in Figure 7, where different level curves of $\Gamma(x, V)$, and these have the slope of $-\left(\frac{\Gamma_{1}}{\Gamma_{2}}\right)$. This in turn implies that $\rho \rightarrow-\infty$

$$
\Gamma(x, V) \rightarrow\left\{\begin{array}{c}
B V \text { if } x<V \\
B V=B x \text { if } x=V \\
\infty \text { if } x>V
\end{array}\right.
$$

which obviously implies that

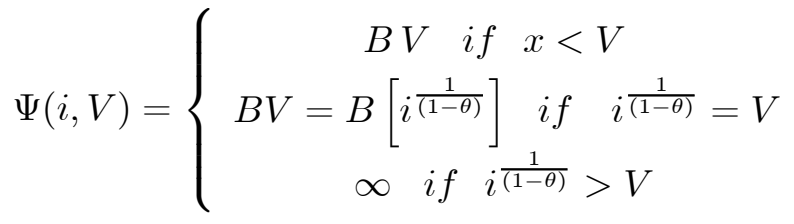




\section{Appendix C}

In this section it is shown how the agent's budget constraint is derived. To ease the notational burden, it will be assumed that there is no investment subsidy $\left(\tau_{i}=0\right)$. The agent consumes his labor income, which in this case is just the income left over after capital is paid its marginal product, and then the cash flow from the firm. Research spending has a return that is internal to the firm. The firm can hire capital at the market rate of return. Of course, the agent must then pay taxes on this amount. Therefore, it is useful to look at the profit-maximization problem faced by the firm.

It is assumed that capital investment is paid out of a firm's retained earnings, and that research spending is deducted as a firm's expense. The production technology is written as $f\left(\tilde{k}_{t}, n_{t}\right)$ rather than

$f\left(\tilde{k}_{t}\right)$ so that the former is constant returns to scale, to reflect that all factors are paid their marginal product, and this will exhaust the firm's output. Let us call this other factor "labor", and its marginal product can be termed the wage $(w)$. Define the firms discounted profits as follows:

$$
\begin{aligned}
& W\left(\tilde{k}_{t}, \tilde{V}_{t} ; \tilde{V}_{t-1}\right) \\
& =\max _{\left(k_{t+1}, v_{t}\right)}\left\{\left(1-\tau_{k}\right)\left[f\left(\tilde{k}_{t}, n_{t}\right)-w n_{t}-\tilde{v}_{t}\right]+\left[\tau_{k} \delta q\left(\tilde{V}_{t-1}\right)\right] \tilde{k}_{t}-\Psi\left(\tilde{\imath}_{t}, \tilde{V}_{t},\right)\right. \\
& \left.\quad+\left(\frac{1}{1+r}\right) W\left(\tilde{k}_{t+1}, \tilde{V}_{t+1}, ; \tilde{V}_{t}\right)\right\}
\end{aligned}
$$

The term $\left[\tau_{k} \delta q\left(\tilde{V}_{t-1}\right)\right]$ should be thought of a being a constant from the perspective of an individual agent, since it is the depreciation deduction for capital. This characterization reflects the fact that the firm's depreciation deduction is based on the real value (i.e. in units of consumption) at that date. Note that $\tilde{\imath}_{t}=\tilde{k}_{t+1}-(1-\delta) \tilde{k}_{t}$, and $\tilde{V}_{t}=\tilde{V}_{t-1}+\tilde{v}_{t-1}$ The firms profit maximization conditions for labor and research spending, respectively, are written as follows:

$$
f_{2}\left(\tilde{k}_{t}, n_{t}\right)=w
$$




$$
\begin{aligned}
\left(1-\tau_{k}\right) & =\left(\frac{1}{1+r}\right) W_{2}\left(\tilde{k}_{t+1}, \tilde{V}_{t+1}, ; \tilde{V}_{t}\right) \\
& =\sum_{j=1}^{\infty}\left(\frac{1}{1+r}\right)^{j}\left[\frac{\partial \Psi\left(\tilde{\imath}_{t+j}, \tilde{V}_{t+j}\right)}{\partial V_{t+j}}\right] \\
& =\sum_{j=1}^{\infty}\left(\frac{1}{1+r}\right)^{j} R_{t+j}
\end{aligned}
$$

where the second part of this equation comes from the envelope condition. The optimization conditions for capital accumulation are written as follows:

$$
\left[\frac{\partial \Psi\left(\tilde{\imath}_{t}, \tilde{V}_{t}\right)}{\partial k_{t+1}}\right]=\left(\frac{1}{1+r}\right) W_{1}\left(\tilde{k}_{t+1}, \tilde{V}_{t+1} ; \tilde{V}_{t}\right)
$$

and

$$
W_{1}\left(\tilde{k}_{t}, \tilde{V}_{t} ; \tilde{V}_{t-1}\right)=\left(1-\tau_{k}\right)\left[f_{1}\left(\tilde{k}_{t}, n_{t}\right)\right]+\tau_{k} \delta q\left(\tilde{V}_{t-1}\right)+(1-\delta)\left[\frac{\partial \Psi\left(\tilde{\imath}_{t}, \tilde{V}_{t}\right)}{\partial k_{t}}\right]
$$

Equations (7.4) and (7.3) can then be combined as follows:

$$
\left(1-\tau_{k}\right)\left[f_{1}\left(\tilde{k}_{t}, n_{t}\right)\right]+\tau_{k} \delta q\left(\tilde{V}_{t-1}\right)+(1-\delta)\left[\frac{\partial \Psi\left(\tilde{\imath}_{t}, \tilde{V}_{t}\right)}{\partial k_{t}}\right]=(1+r)\left[\frac{\partial \Psi\left(\tilde{\imath}_{t-1}, \tilde{V}_{t-1}\right)}{\partial k_{t-1}}\right]
$$

or

$$
\left(1-\tau_{k}\right)\left[f_{1}\left(\tilde{k}_{t}, n_{t}\right)\right]+\tau_{k} \delta q_{t-1}+(1-\delta) q_{t}=(1+r) q_{t-1}
$$

Equation (7.1) equates the marginal product of labor (or the remaining factor, other than capital) to its price. Equation (7.2) states that the after-tax marginal cost of a unit of research spending, must then equal the marginal return, in terms of lowering the marginal cost of future investment. And lastly, equation (7.6) equates the after-tax marginal return to capital to the economy's interest rate.

The firm's one-period profits, including the implicit value of the research activity, are then as follows: 


$$
\begin{aligned}
\pi_{t}= & \tilde{k}_{t}\left[\left(1-\tau_{k}\right)\left[f_{1}\left(\tilde{k}_{t}, n_{t}\right)\right]+\tau_{k} \delta q_{t-1}+q_{t}(1-\delta)\right] \\
& +R_{t} \tilde{V}_{t}-q_{t} \tilde{k}_{t+1}-\left(1-\tau_{k}\right) \tilde{v}_{t} \\
= & \tilde{k}_{t}\left[\left(1-\tau_{k}\right)\left[f_{1}\left(\tilde{k}_{t}, n_{t}\right)\right]+\tau_{k} \delta q_{t-1}\right]+R_{t} \tilde{V}_{t}-q_{t} \tilde{\nu}_{t}-\left(1-\tau_{k}\right) \tilde{v}_{t}
\end{aligned}
$$

Let $\tau_{d}$, and $\tau_{w}$ denote the dividend and labor income tax rates, respectively. The agent's budget constraint then must show that consumption equals wage payments, plus the firm's cash flow, which is then written as follows:

$$
\begin{aligned}
c_{t}= & \left(1-\tau_{d}\right) \pi_{t}+\left(1-\tau_{w}\right) w n \\
= & \left(1-\tau_{d}\right)\left(\tilde{k}_{t}\left[\left(1-\tau_{k}\right)\left[f_{1}\left(\tilde{k}_{t}, n_{t}\right)\right]+\tau_{k} \delta q_{t-1}\right]+R_{t} \tilde{V}_{t}-q_{t} \tilde{\imath}_{t}-\left(1-\tau_{k}\right) \tilde{v}_{t}\right) \\
& +\left(1-\tau_{w}\right) w n
\end{aligned}
$$

or

$$
\begin{aligned}
c_{t}= & \left(1-\tau_{d}\right) \tilde{k}_{t}\left(\left(1-\tau_{k}\right)\left[f_{1}\left(\tilde{k}_{t}, n_{t}\right)\right]+\tau_{k} \delta q_{t-1}\right)+\left(1-\tau_{d}\right) R_{t} \tilde{V}_{t}-\left(1-\tau_{d}\right)\left(1-\tau_{k}\right) \tilde{v}_{t} \\
& -q_{t} \tilde{\tau}_{t}\left(1-\tau_{d}\right)+\left(1-\tau_{w}\right) w n
\end{aligned}
$$

By replacing $\left(1-\tau_{d}\right) \tilde{\imath}_{t}$ with $i_{t},\left(1-\tau_{d}\right) \tilde{v}_{t}$ with $v_{t},\left(1-\tau_{d}\right) \tilde{V}_{t}$ with $V_{t}$ and $\left(1-\tau_{d}\right) \tilde{k}_{t}$ with $k_{t}$, this last budget constraint is the equivalent of equation (3.1), when the other taxes are set as follows: $\tau_{i}=\tau_{w}=0$. However, it should be clear that written in this manner, the research subsidy $\left(\tau_{r}\right)$ takes on the value of the capital tax rate $\left(\tau_{k}\right)$. If there are even additional research subsidies, then $\tau_{r}>\tau_{k}$.

As is well-known, the dividend tax does not distort the investment or research spending decision if these activities are financed out of retained earnings. However, the capital or profit tax does lower the after-tax return to investment. As is shown above, there is no distortion in the optimization condition for research spending. 


\section{References}

[1] Aiyagari, S. Rao, "Optimal Capital Income Taxation with Incomplete Markets, Borrowing Constraints, and Constant Discounting," Journal of Political Economy,103(6), (1995): pp. 1158-1175.

[2] Gordon, Robert, The Measurement of Durable Goods Prices, Chicago: University of Chicago Press, (1990).

[3] Gort, Michael, Jeremy Greenwood, Peter Rupert, "Measuring the Rate of Technological Progress in Structures" Review of Economic Dynamics, 2(1), (January 1999): pp. 207-230.

[4] Greenwood, Jeremy, Zvi Hercowitz, and Per Krusell, "Long-Run Implications of InvestmentSpecific Technological Change," American Economic Review, 87(3), (June 1997): pp. 342-362.

[5] Greenwood, Jeremy, Zvi Hercowitz, and Per Krusell, "The Role of Investment-Specific Technological Change in the Business Cycle," European Economic Review, 44(1), (January 2000): pp. 91-115.

[6] Howitt, Peter, "Steady Endogenous Growth With Population and R\&D Inputs Growing" Journal of Political Economy, 107(4), (August 1999): pp. 715-730.

[7] Jorgenson, Dale W. "Information Technology and the U.S. Economy," American Economic Review, 91(1), (March 2001):pp. 1-32

[8] Jones, Charles, "R\&D Models of Economic Growth," Journal of Political Economy, 103, (August 1995): pp. 759-784.

[9] Lucas, Robert E. Jr. "Supply-Side Economics: An Analytical Review" Oxford Economic Papers, 42, (April, 1990): pp. 293-316.

[10] Rebelo, Sergio, "Long-Run Policy Analysis and Long-Run Growth," Journal of Political Economy, 99(3), (June 1991): pp. 500-521.

[11] Romer, Paul M., "Increasing Returns and Long Run Growth," Journal of Political Economy, 94(5), (October 1986): pp. 1002-1037.

[12] Stokey, Nancy L., Sergio Rebelo, "Growth Effects of Flat Taxes", Journal of Political Economy, 103(3), (June 1995): pp. 519-550. 
Figure 1

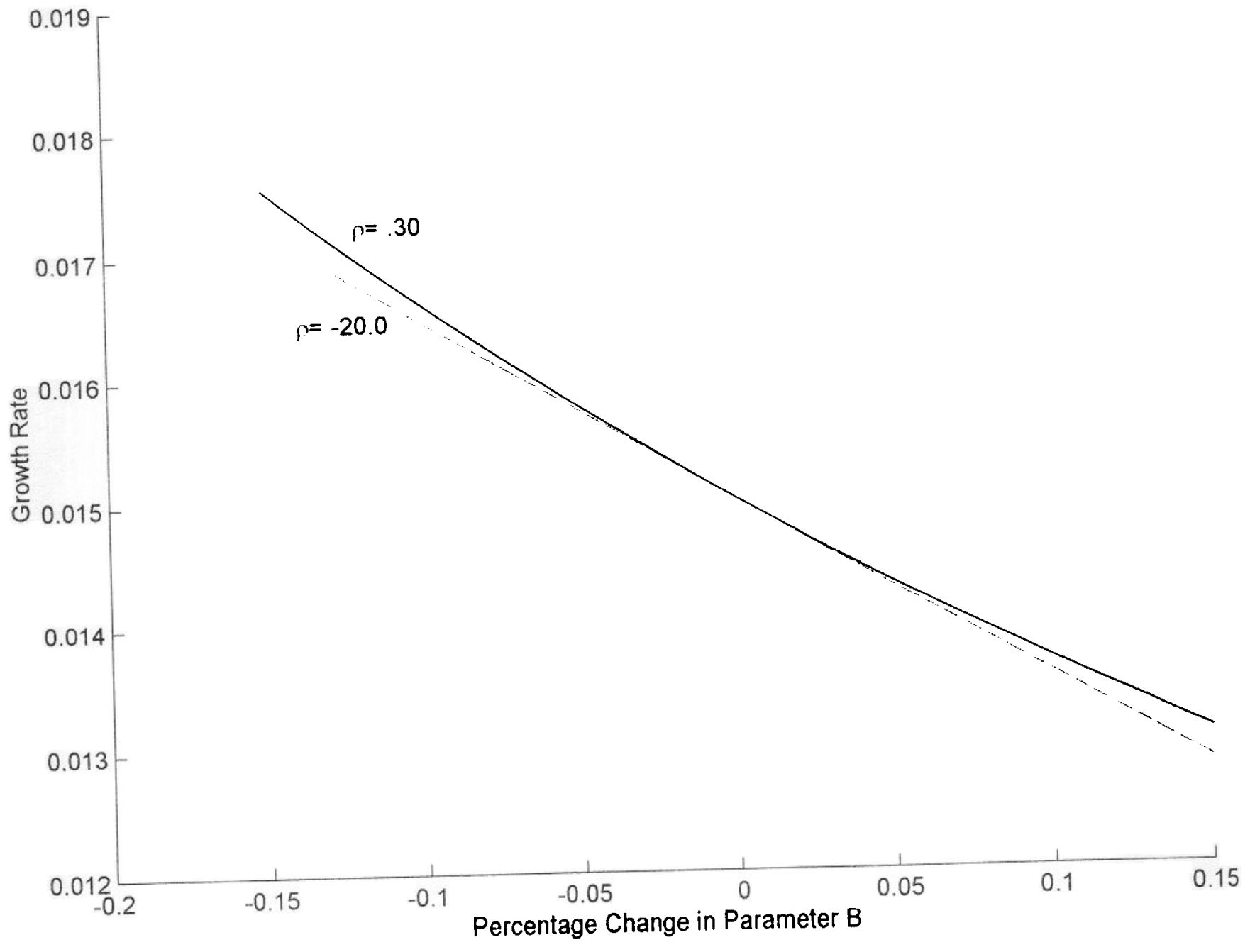


Figure 2

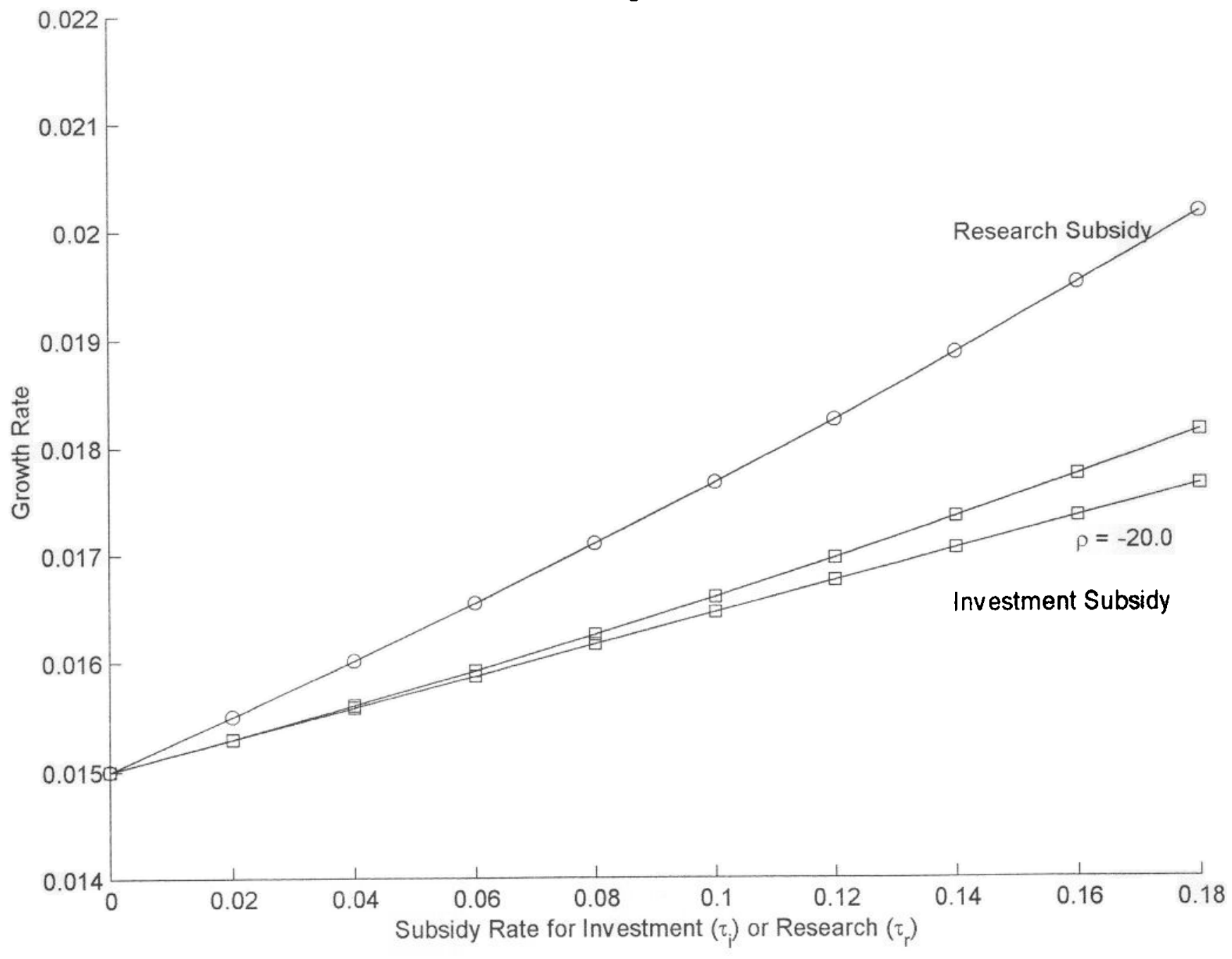


Figure 3

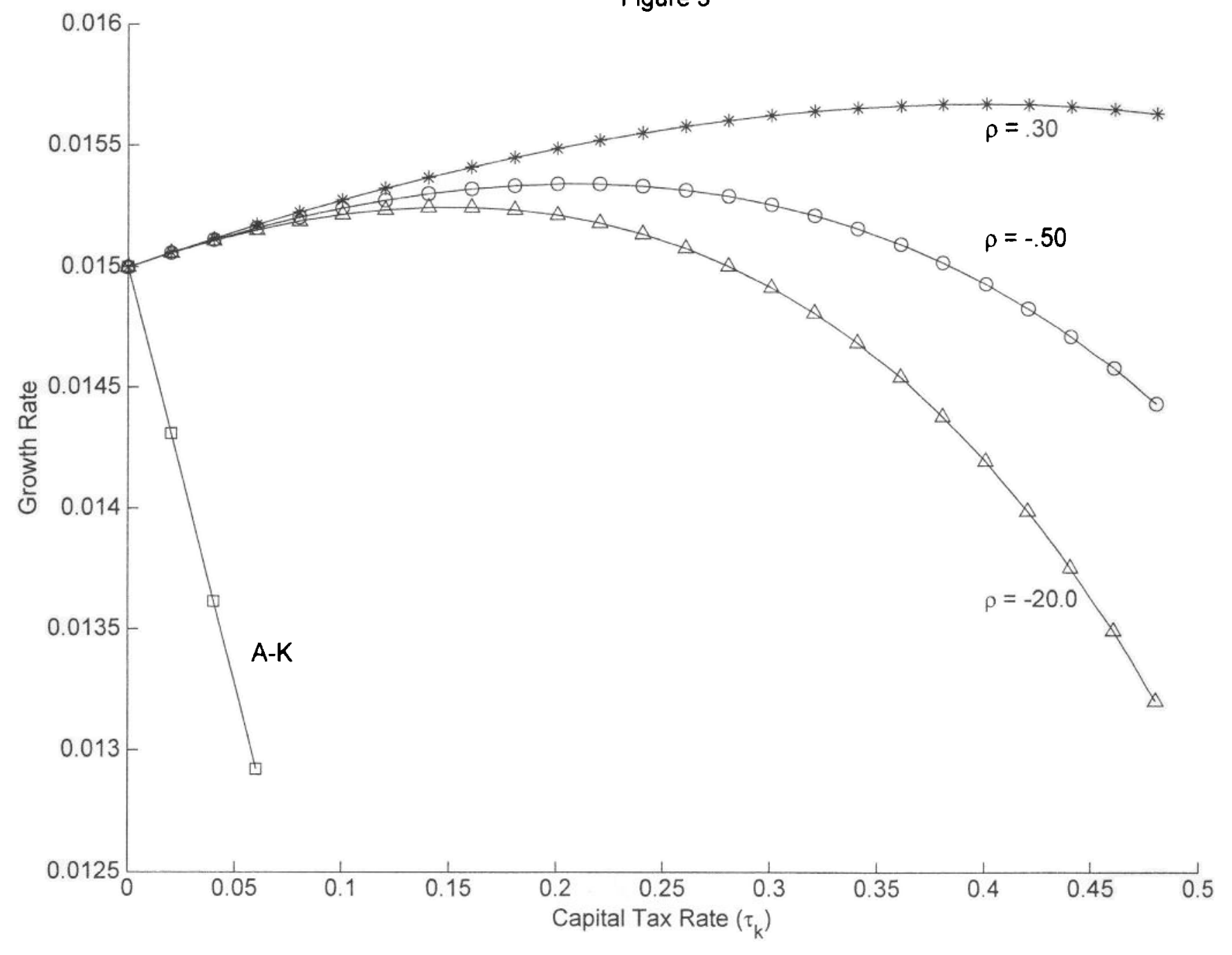


Figure 4

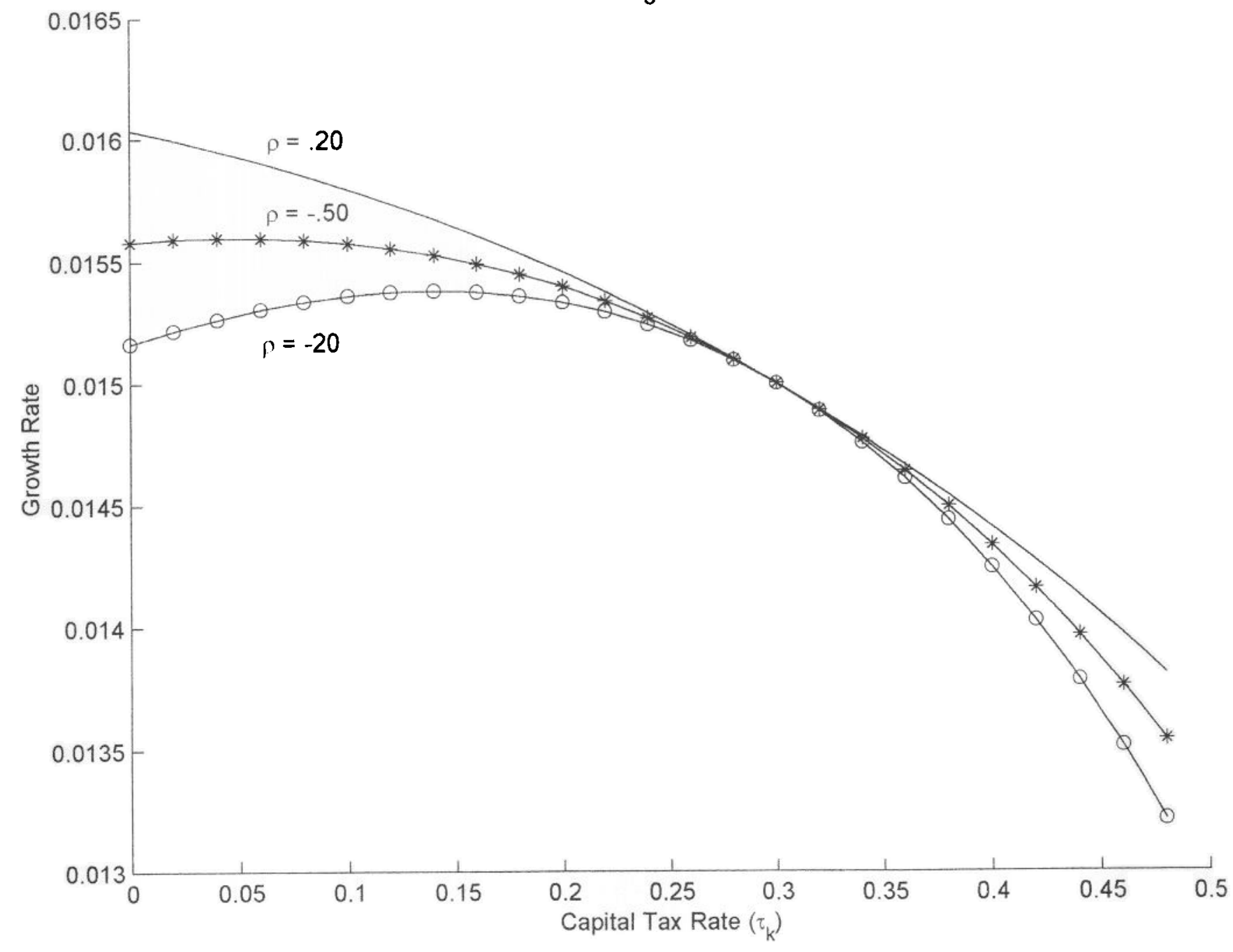


Figure 5

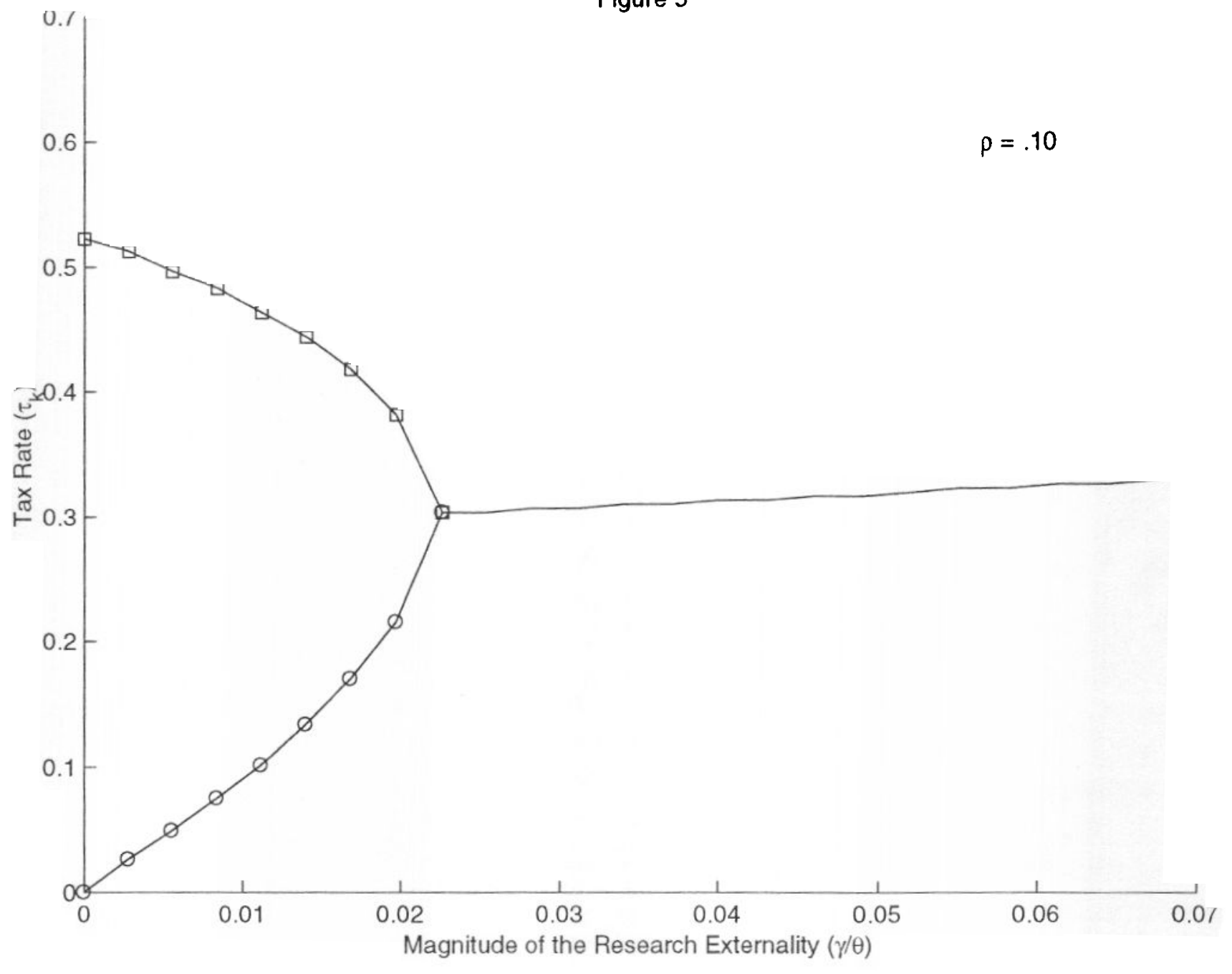




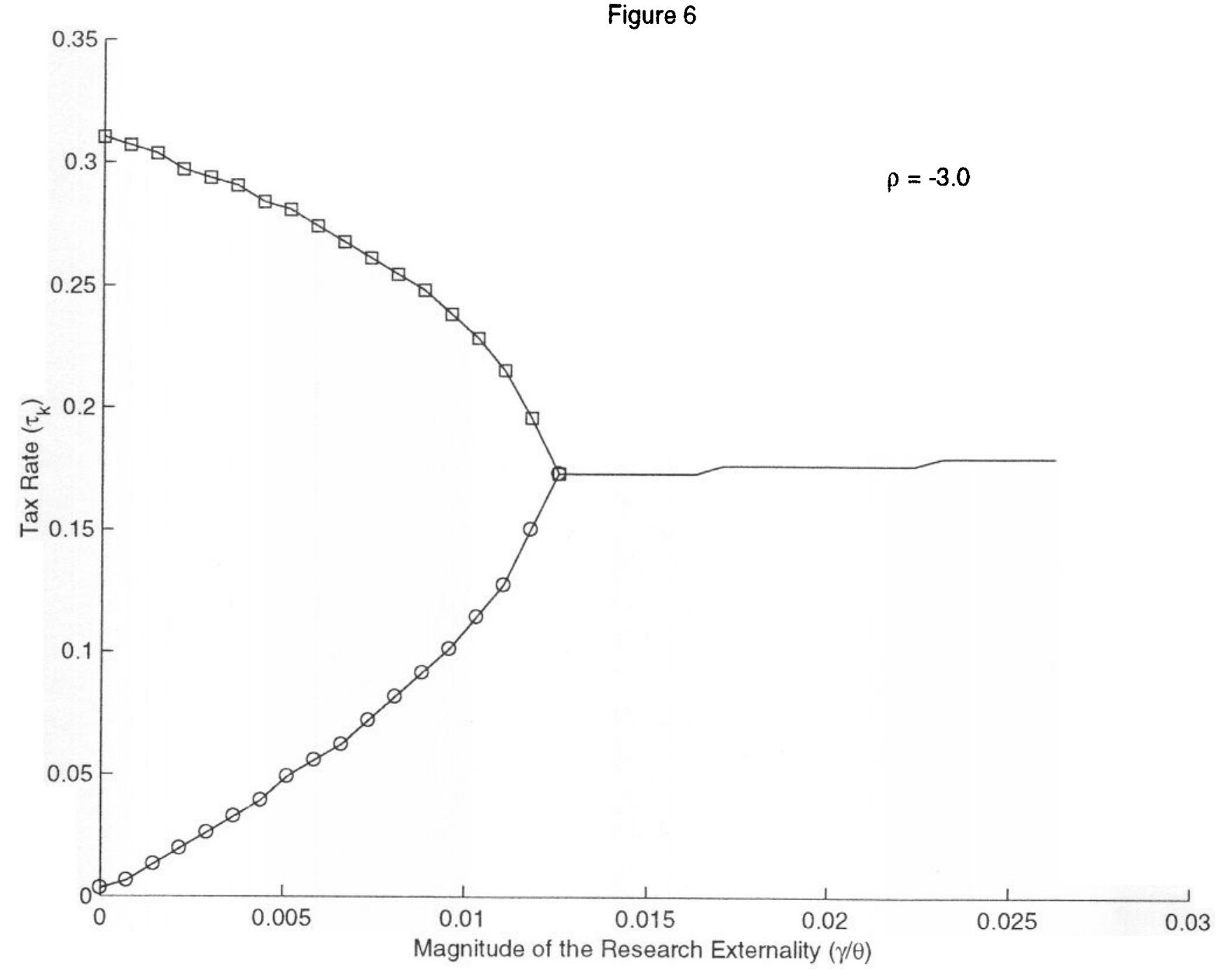


Figure 7

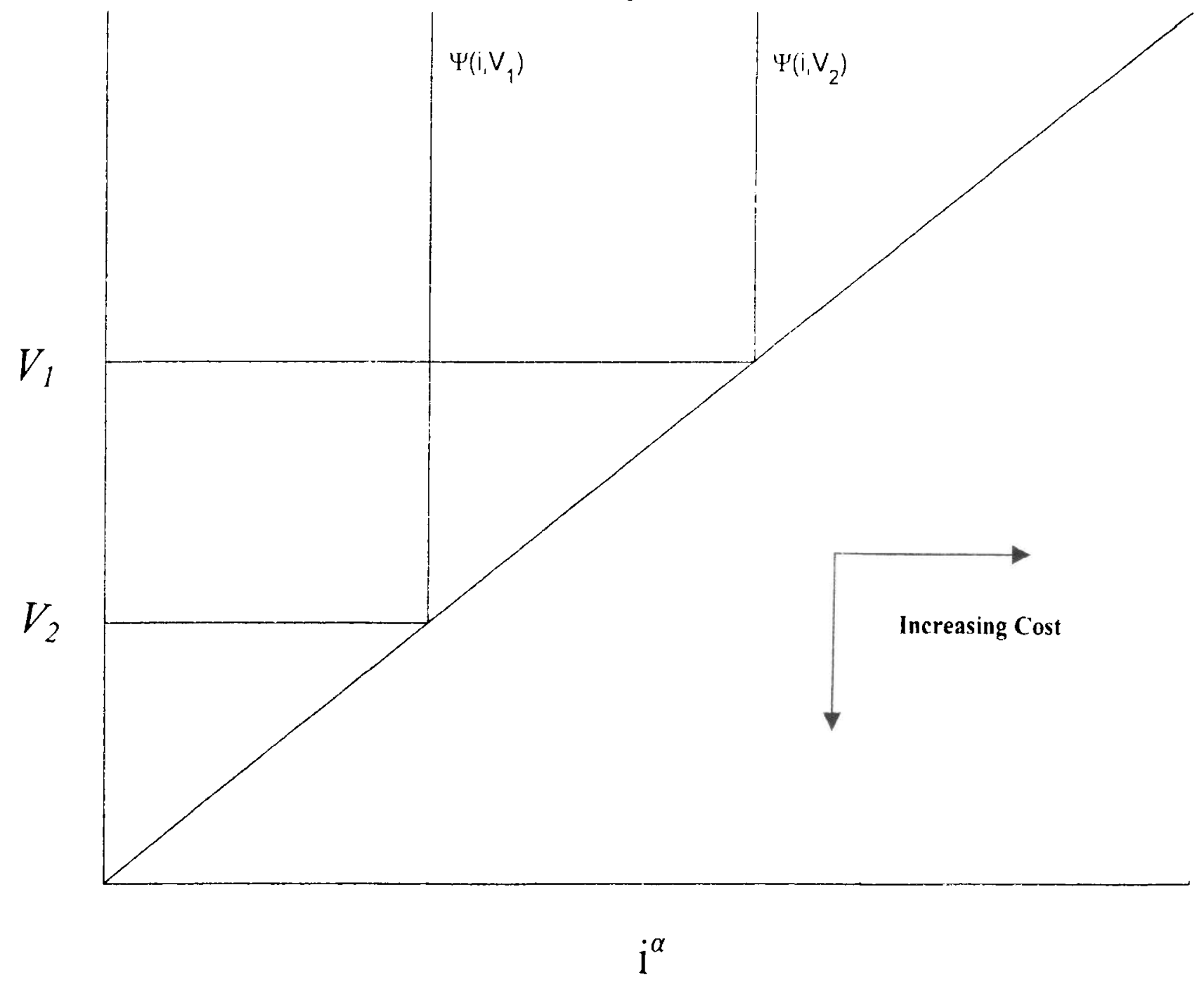

